\title{
BENEDETTO DI ANIANE EPITOMATORE DI GREGORIO MAGNO E COMMENTATORE DEI RE?*
}

\author{
L'EPITOME MARRIER
}

Nel 1977 Gabriella Braga identificava l'epitome dei Moralia di Gregorio Magno eseguita da Oddone di Cluny, di cui parla la Vita del grande abate composta da Giovanni Salernitano ${ }^{1}$, con quella conservata nel codice Parigino lat. $2455^{2}$. In questo modo veniva a ritrovarsi senza attribuzione un'altra epitome dell'opera gregoriana, che era stata pubblicata sotto il nome di Oddone da Martin Marrier nel $1617^{3}$, ma la cui paternità era già stata contestata nel 1974 da Fidel Rädle in base alla datazione dei manoscritti più antichi ${ }^{4}$. Dopo

* Nel corso dell'articolo verranno citati in forma abbreviata i seguenti repertori : Stegmüller $=$ F. Stegmüller, Repertorium biblicum medii aevi, Madrid 1950-1961; $\mathrm{CPL}=\mathrm{E}$. Dekners, Clavis patrum Latinorum, Steenbrugge $1995^{3}$; CPPeMA = J. MACHIElsen, Clavis patristica pseudo epigraphorum medii aevi, Turnhout 1990-; CPG = Clavis patrum Graecorum, I-V, Turnhout 1983-87; CSLMAG = Clavis scriptorum Latinorum medii aevi. Auctores Galliae 735-98\%, A-E, Turnhout 1994. Un'anticipazione della ricerca di cui sono qui esposti i risultati è stata presentata al IX Convegno Internazionale della Società Internazionale per lo Studio del Medioevo Latino, dal titolo Quindici anni di esperienze nella critica del testo mediolatino. Dibattito teorico. Letture mediolatine. Nuovi strumenti, tenutosi a Firenze il 7-8 aprile 2006. Per suggerimenti, discussioni e materiali ringrazio Dom Pierre-Maurice Bogaert, François Dolbeau, Michael Gorman, Rossana Guglielmetti, Fabrizio Martello, Giovanni Orlandi, Anne-Marie Turcan-Verkerk.

1. Cap. 20; PL 133, col. 52.

2. G. Braga, Problemi di autenticità per Oddone di Cluny : l'epitome dei Moralia di Gregorio Magno, "Studi medievali " ser. III, 18 (1977), pp. 611-711. L’epitome di Oddone si ritrova anche nel codice di Tolosa, Bibliothèque Municipale 41 (cfr. Catalogue général des manuscrits des bibliothéques publiques des Départements, VII, Paris 1885 , p. 19).

3. Sancti Odonis abatis Cluniacensis II Moralia in Job libri XXXV, Paris 1617. L'edizione del Marrier venne poi riprodotta nella Maxima Bibliotheca Patrum Lugdunensis, XVII, Lyon 1677, coll. 250-456 e nella PL 133, coll. 107-512. L'opera è registrata in Stegmülleer, IV, 6118 e in CPPeMA II A, n 2242.

4. Studien zu Smaragd von Saint-Mihiel München 1974, pp. 45-9. In precedenza ancora R. WAsselynck, Les compilations sildes Moralia in Iob du viI au xII siècle, "Recherches de théologie ancienne et attribuiva l'epitome a Oddone. 
avere condotto un'attenta analisi degli elementi esterni e interni dell'opera, che andava ad aggiungersi alle osservazioni di Rädle sul suo prologo metrico, Braga concludeva che la composizione dell'epitome sembrava potersi collocare tra gli ultimi anni dell'VIII secolo e la prima metà del IX, in un periodo per il quale non erano fino a quel momento noti né commenti a Giobbe, né abbreviazioni dei Moralia.

Chiameremo questa abbreviazione, seguendo Braga, Epitome Marrier, e ricapitoleremo sulla scorta dei suoi studi i dati principali che la riguardano. Del testo sono segnalati finora tre manoscritti : il Bodleiano Laud. misc. 456, scritto a giudizio di Bischoff nella Francia centrale, forse nella regione di Orléans, nel secondo quarto del IX secolo $^{5}$; il Sangallese 205, pure della prima metà del IX secolo, attribuito alla Francia meridionale ${ }^{6}$; e il Vaticano Reg. lat. 306, datato da Wilmart alla seconda metà dell'XI secolo e già in possesso della biblioteca di Cluny ${ }^{7}$. Dei tre, solo quest'ultimo attribuisce il testo a Oddone; il codice Bodleiano è mutilo della prima parte, e il testo è perciò privo di elementi di titolazione, mentre nel Sangallese, che riporta l'opera in forma completa, essa non presenta nel titolo indicazioni d'autore. Braga ha ricostruito che l'edizione Marrier riproduce appunto il codice Reginense ${ }^{8}$ e ricava da esso l'attribuzione a Oddone; attribuzione nata con ogni probabilità proprio a Cluny intorno all'epoca in cui fu scritto questo codice, quando si volle erroneamente identificare con questa l'epitome dei Moralia effetti-

5. Braga, Problemi di autenticità cit., pp. 691-4; B. Bischoff, Katalog der festländischen Handschriften des neunten Jahrhunderts (mit Ausnahme der wisigotischen), II, Wiesbaden 2004, p. $382\left(n^{\circ} 3868\right)$.

6. Braga, Problemi di autenticità cit., pp. 689-91, dove alla nota 36 si riferisce anche l'opinione di Bischoff in proposito. Il codice sembra essere giunto a San Gallo ancora nel pieno IX secolo, perché ad esso corrisponderà l'indicazione del catalogo di Grimaldo (841-872) Item [di Gregorio] libri XXXV excerpti ab eisdem Moraliarum (sic) libris in codice uno (P. Lehmann, Mittelalterliche Bibliothekskataloge Deutschlands und der Schweiz, I : Die Bistümer Konstanz und Chur, München 1918, p. 72, r. 24). Una scheda sul manoscritto e una riproduzione della p. 10 si trovano in Gregorio Magno e l'invenzione del medioevo, a cura di L.G.G. Ricci, Firenze 2006, pp. 92-95.

7. A. Wilmart, Codices Reginenses Latini, II, Città del Vaticano 1945, p. 154; BraGA, Problemi di autenticità cit., pp. 694-7. Il codice è già menzionato, al numero 303, nell'inventario dei libri della biblioteca di Cluny redatto ai tempi dell'abate Ugo I (1049-1109; pubblicato da L. Delisle, Le cabinet des manuscrits de la Bibliothèque nationale, II, Paris 1874, pp. 458-481, a p. 469; la datazione si deve a V. von Büren, Le grand catalogue de la bibliothèque de Cluny, insLe gouvernement d'Hugues de Semur à Cluny, Cluny 1988, pp. 245-63); l'item fa partéridella lista originaria, e non è un'addizione successiva.

8. Braga, Problemi di autenticità cit.,
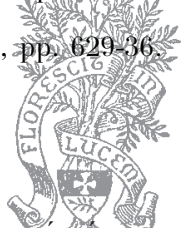
vamente scritta da Oddone, della quale si aveva notizia dalla biografia dell'abate composta da Giovanni Salernitano ${ }^{9}$.

Il testo dell'Epitome Marrier non appare diverso da altre riduzioni medievali dei Moralia $^{10}$ quanto alla drastica eliminazione delle innumerevoli digressioni presenti nel testo, che prendono spunto per lo più dall'esposizione di passi biblici paralleli; l'opera gregoriana finisce perciò per perdere la sua fisionomia originaria di grande enciclopedia morale per diventare un più pratico commentario continuo al libro di Giobbe. Essa presenta però una significativa peculiarità strutturale nella costituzione di una griglia sistematica sulla quale viene progressivamente disposto il materiale esegetico. Nell'Epitome Marrier il libro di Giobbe è suddiviso in unità testuali minime (versetti o articoli di versetto), ognuno dei quali è seguito in successione dalle interpretazioni esegetiche (storica, allegorica, morale), ricavate alla lettera dai Moralia o riassunte da essi in modo estremamente fedele. L’opera gregoriana, pur procedendo a un'analoga analisi, manteneva invece - soprattutto nei primi libri - una struttura più lasca, nella quale il testo biblico era diviso in pericopi di maggiore estensione, che consentiva di ottenere migliori risultati espositivi e di aprire frequenti finestre su argomenti correlati ${ }^{11}$. Il lavoro dell'epitomatore ha

9. Al piede dell'ultimo foglio del codice $(221 \mathrm{v})$ si legge un colophon, di mano più recente rispetto a quelle che hanno lavorato al testo: Istum librum qui per longum tempus perditus fuerat recuperauit frater Petrus tunc armarius Clun(iaci) de manu Duranni Galeis; prima della nota è visibile una lunga rasura, oggi indecifrabile, dove forse erano contenute originariamente le informazioni riportate oggi nel colophon. Sia Petrus armarius che Durannus sono identificabili con personaggi vissuti durante l'abbaziato di Ugo I a Cluny; del primo si hanno notizie anche sotto il successore di Ugo, Ponzio (1109-1122), mentre del secondo si sa che fu un rinomato scriba. La recuperatio di cui si parla nel colophon è stata interpretata come l'indicazione del recupero fisico di questo preciso volume, che sarebbe già stato posseduto dalla biblioteca di Cluny e in seguito sarebbe stato perduto. Tuttavia il fatto che la recuperatio si sia compiuta de manu Duranni Galeis e che costui fosse un copista, o più probabilmente il capo dello scriptorium, farebbe piuttosto pensare che sia alluda al ritrovamento di un'opera che si riteneva perduta - e non di questo specifico manoscritto - e che la presente copia sia la conseguente trascrizione. Si può pensare cioè che l'armarius Pietro, visto che fra le opere di Oddone era segnalata un'adbreviatio dei Moralia che a Cluny non si trovava, l'abbia fatta ricercare e abbia creduto di individuarla in un manoscritto esterno, e ne abbia fatta approntare da Duranno e dai suoi sottoposti una copia per la biblioteca dell'abbazia. Ciò sembrerebbe meglio corrispondere anche alla datazione paleografica della scrittura, cronologicamente troppo vicina all'attestazione del codice nella biblioteca di Cluny perché si possa parlare di una sua perdita per longum tempus, nonché alla precoce presenza del codice nel catalogo dell'epoca di Ugo I.

10. Sulle epitomi dei Moralia nell'alto medioevo cfr. Wasselynck, Les compilations des Moralia in Iob cit.; G. BRaga, Moralia in Iob : Epitomi dei secoli viI-X e loro evoluzione, in Grégoire le Grand, Paris 1986 (Colloques internationaux du CNRS), pp. 5618 .

11. Una dettagliata analisi del metoddo eorenporsitivo dell'epitome in Braga, Problemi di autenticità cit., pp. 636-56. 
comportato perciò non una semplice riduzione, ma anche un'accurata ristrutturazione del testo, sulla base di una sistematica schedatura delle sezioni dell'opera di partenza.

L'Epitome Marrier è preceduta da due prologhi, dei quali diamo in appendice una nuova edizione. Il primo dei due è in prosa, ed espone le circostanze del lavoro, la sua strategia e i suoi scopi; il secondo è in esametri, e costituisce una geminatio poetica del precedente, senza nulla aggiungervi nel contenuto. I due prologhi si leggono in entrambi i testimoni completi dell'opera; nel codice Reginense essi precedono immediatamente il testo, mentre in quello di San Gallo ad essi fa seguito, prima dell'inizio dell'epitome vera e propria, una sorta di accessus al libro di Giobbe, costituito da brevi estratti di autorità patristiche ${ }^{12}$. Nonostante questi prologhi siano piuttosto ampi e dettagliati, nulla vi vien detto né dell'autore, né del luogo di composizione; il loro tenore non è quello di una lettera di dedica, né si fa menzione di un eventuale destinatario. Il prologo in prosa fornisce comunque alcune informazioni interessanti. L'autore dichiara di avere conosciuto e apprezzato i Moralia, ma di essere rimasto spaventato dalla mole e dalla complessa struttura dell'opera; di avere trovato la difficoltà maggiore nella presenza, all'interno del commento principale a Giobbe, di continue digressioni, generate dall'inserimento di passi tratti dai più diversi libri della Bibbia, a loro volta analizzati da Gregorio ${ }^{13}$, digressioni che erano a suo tempo state estratte, ordinate e sistemate in appositi volumi da Paterio ${ }^{14}$; di avere due

12. Descritto da Braga, Problemi di autenticita cit. pp. 688-9. Le fonti sono Girolamo, Liber Hebraicarum quaestionum in Genesim, il prologo di Gregorio Magno ai Moralia, e la prefazione al libro di Giobbe nella Vulgata geronimiana.

13. In proposito l'epitomatore scrive : "Is etenim mirabilis doctor, diuinis imbribus haustus, studuit luculento enodare adfatu eas quae in exponendo menti occurrerent sententias patrum; ex quibus protensis numerosa in praefatam historiam contraxit uolumina ». Le digressioni dei Moralia sono in realtà costituite dall'inserzione non di sententiae patrum, ma di ulteriori passi biblici, tratti da libri diversi della Scrittura e non più da Giobbe, che Gregorio a loro volta spiegava e commentava; e furono appunto tali sententiae bibliche che vennero poi estratte e riordinate propriis uoluminibus da Paterio (v. nota seguente). A meno di errori nella trasmissione - ma appare arduo pensare che la parola patrum sia corruttela di altra qualifica degli scrittori sacri, come prophetarum o patriarcharum - l'autore del prologo usa un'espressione molto approssimativa; si può comunque osservare che in seguito nello stesso prologo sententia è usato come termine generico per indicare un passo della Bibbia (« unicuique sententiae misticum moralemque, sicut repperi, subieci sensum »).

14. "Quas [sententias] nempe norunt, quibus sacra non latet Scriptura, a sancto uiro Paterio nomine mirabili opere abstractas propriisque uoluminibus redditas, lucida sibi reposuisse uolumina ". Il soggetto sembrerebbe Gregorio : dopo avere prodotto i suoi ricchi volumi su Giobbe (numerosa uplumplete attraverso l'incarico da lui affidato a Paterio ne predispose degli altri moltodentari (Lucida uolumina) di esegesi varia. Il Liber testimoniorum di Paterio (CPL 1718) diflegge ancora soltanto nell'edizione dei

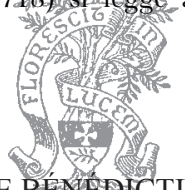


anni prima a sua volta composto un commentario ai libri dei Re, costituito da un insieme di sententiae sul modello pateriano, ricavate in particolare da Gregorio ${ }^{15}$. Quanto ai criteri di composizione dell'epitome, l'autore dice di essersi limitato a eliminare le parti dei Moralia che commentavano libri diversi della Bibbia ${ }^{16}$; di avere abbreviato e sintetizzato le parole di Gregorio senza nulla aggiungere di proprio ${ }^{17}$; di avere più strettamente unito i commenti morale e mistico alla sententia del libro di Giobbe cui si riferivano ${ }^{18}$. A quanto si riesce a comprendere dalla premessa, a tratti piuttosto involuta, l'epitomatore sembra concepire dunque il suo lavoro come una destrutturazione dei Moralia complementare a quella di Paterio: mentre il segretario di Gregorio aveva estratto dall'opera i testimonia biblici estranei a Giobbe con il relativo commento gregoriano, egli procede invece ora a una riscrittura continua, riordinata e sintetica delle sole parti relative a Giobbe, trascurando deliberatamente le citazioni diverse. Egli segnala infine di avere seguito nell'epitome un particolare metodo di presentazione del materiale, evidenziando in rosso (minio) l'inizio dei passi biblici oggetto di commento (primas historiae litteras), e ciò discretionis causa, ossia per poter seguire con più facilità il testo ${ }^{19}$; espediente di cui sembra essere rimasta qualche traccia nella tradizione manoscritta ${ }^{20}$.

Veniamo così a sapere che l'attività esegetica dell'autore dell'Epitome non è occasionale o limitata a Giobbe; né occasionale è il suo interesse per Gregorio, visto che egli conosce gli estratti gregoriani

Maurini (PL 79, 683-916). Su quest'opera cfr. A. Wilmart, Le recueil grégorien de Paterius et les fragments wisigothiques de Paris, "Revue Bénédictine ", 39 (1927), pp. 81104; R. Étaix, Le Liber testimoniorum de Paterius, "Revue des sciences religieuses ", 32 (1958), pp. 66-78; F. Clark, The Pseudo-Gregorian Dialogues, Leiden 1987 (Studies in the History of Christian Thought 37-38), pp. 94-100; P. MeyvaErt, The Enigma of Gregory the Great's Dialogues : A Response to Francis Clark, "Journal of Ecclesiastical History ", 39, 1988, pp. 335-381. Sull'opera sta preparando ora uno studio Fabrizio Martello.

15. «Et ipse ante biennium in Regnorum libro aggregatis omnibus patrum sententiis, maxime autem sanctissimi papae Gregorii, unum quem non puto temnendum coniunxi libellum ".

16. "Eas dumtaxat diuersorum librorum prolixo sermone expositas, quas supra taxaui, linquens sententias, non abiciens ut prauas quas segregatim habeo ut utiles ».

17. "Sensum non meis, sed iam saepe praefati uiri uerbis expositum, breuiter adtraxi, ut potui" ".

18. "Atque lectionis causae compendio, unicuique sententiae misticum moralemque, sicut repperi, subieci sensum, ne uagans animus dum huc illucque quaereret sensum, ut saepe adsolet, amitteret intellectum ».

19. "Libuit etiam primas historiae litterds discretionis causa minio scribere, ut dum historia agnoscitur, expositio historiae uthlins carpatur, ne forte dum a rudibus ignoratur sensus patenter expressus obscuriüs moplectur".

20. Nei primi fogli del codice Reginenseli tenmi biblici sono in effetti rubricati.

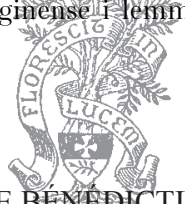


di Paterio e che le opere del grande pontefice hanno avuto una posizione privilegiata all'interno del precedente commentario ai Re. Queste informazioni delineano meglio il profilo dell'epitomatore; non bastano tuttavia ad assegnargli un nome ${ }^{21}$.

Il commentario ai Re del Parigino lat. 15679

E possibile rintracciare il libellus sui Re che l'autore del prologo dell'Epitome Marrier dice di avere composto in precedenza? Nessuno dei commentari a questi libri della Bibbia compresi nel repertorio di Stegmüller pare, per epoca o per caratteristiche, adattarsi alla bisogna ${ }^{22}$. Un ulteriore commento è stato però recentemente segnalato da Michael Gorman nell'importante codice Parigino lat. 15679, una vasta miscellanea esegetica volta a coprire l'intero testo biblico ${ }^{23}$; un manoscritto esemplato per incarico di Teodolfo di Orléans, probabilmente a Micy - il monastero suburbano che egli aveva fatto riformare grazie al contributo di monaci inviati da Benedetto di Aniane $^{24}$-, dove è attestato anche in seguito, e concepito quasi certamente come sussidio alla grande Bibbia teodolfina, con i manoscritti della quale (come il Parigino lat. 9380 e quello del Cha-

21. Sulla tradizione esegetica sui libri dei Re fino all'età carolingia cfr. S. Cantelli, Angelomo e la scuola esegetica di Luxeuil, I, Spoleto 1990, pp. 301-10.

22. Un elenco di questi commentari si trova in Braga, Problemi di autenticità cit., p. 657, n. 229, dove si citano quelli di Beda (Stegmüller II, 1606), di Claudio di Torino (Stegmüller II, 1954-56), di Rabano Mauro (Stegmüller V, 7033-36), di Angelomo di Luxeuil (STEgmüller II, 1335-38); ad essi può essere aggiunto quello compreso nel codice Karlsruhe, Badische Landesbibliothek, Aug. perg. CXXXV (Stegmüller VI, 9355-56, che ne riporta degli stralci).

23. M. M. Gorman, Theodulf of Orléans and the Exegetical Miscellany in Paris lat. 15679, "Revue Bénédictine " 109 (1999), pp. 278-323. In precedenza cfr. B. Fischer, Bibeltext und Bibelreform unter Karl dem Großen, in Karl der Große: Lebenswerk und Nachleben, II : Das geistige Leben, Düsseldorf 1965, pp. 156-216, a p. 177 [poi in B. F., Lateinische Bibelhandschriften im frühen Mittelalter, Freiburg 1985, pp. 101-202, a p. 138]; B. Bischoff, Die Bibliothek im Dienste der Schule, in La scuola nell'Occidente latino dell'alto medioevo, Spoleto 1971, pp. 385-415 (Atti delle Settimane di studio del Centro Italiano di Studi sull'Alto Medioevo, 19) [poi in B. B., Mittelalterliche Studien, III, Stuttgart 1981, pp. 213-33]; E. Dahlhaus-Berg, Nova antiquitas et antiquitas nova. Typologische Exegese und isidorianisches Geschichtsbild bei Theodulf von Orléans, Köln - Wien 1975 (Kölner historische Abhandlungen 23), p. 69. Il commentario all'Apocalisse contenuto nella miscellanea teodolfina è stato di recente pubblicato da $\mathrm{R}$. Gryson, Commentaria minora in Apocalypsin Johannis, Turnhout 2003 (CCSL 107), pp. 299-337.

24. Ardo, Vita Benedicti abbatis Ananiensis et Indensis, cap. 24 (ed. G. Waitz, MGH, SS XV, 1, pp. 198-220, p. 209). Sulfasstaria di questo monastero cfr. la voce di Th. Head nel Lexikon des Mittelalters, J1 Mitnefen 1993, coll. 612-3 e la bibliografia qui citata. 
pitre de la Cathédrale di Le Puy) presenta affinità di ordine codicologico e paleografico.

La miscellanea esegetica, dettagliatamente descritta da Gorman, si sviluppa nella successione dei vari libri della Bibbia, dedicando uno spazio proporzionalmente maggiore all'Antico Testamento. Essa raccoglie per lo più commentari preesistenti, trascritti alcuni in forma integrale, molti di più in forma epitomata. Ai quattro libri dei Re sono dedicati due testi: il primo (pp. 65-75) sono le XXX quaestiones in Regum di Beda (CPL 1347) ${ }^{25}$, che vengono riportate integralmente; il secondo (pp. 75-83), che è quello che qui interessa, è intitolato Sententiae expositae in Regnorum libris de diversis doctoribus, ed ̀̀ costituito da 32 estratti di auctoritates patristiche a commento di passi dei Re differenti da quelli oggetto delle Quaestiones bediane. La disposizione delle Sententiae nel manoscritto evidenzia che esse, nel momento in cui vennero trascritte nel codice, furono intese come testo ‘aperto', prevedendo cioè la possibilità di eventuali ampliamenti successivi; e che questa possibilità venne effettivamente realizzata. Si spiega cosi il fatto che i 32 estratti siano preceduti da un sommario che si riferisce solo ai primi 28 di quelli che si leggono poi a testo; che gli ultimi quattro numeri del sommario (XXV-XXVIII) siano stati scritti ciascuno in un momento diverso, e forse anche da una mano diversa, date le caratteristiche delle penne e degli inchiostri usati; che al termine del sommario sia stato lasciato ampio spazio bianco per poter aggiungere altri lemmi. Un'analoga situazione si rileva dalla disposizione del testo : le sententiae successive alla XXIV sono vergate in momenti diversi, e presentano vari elementi di irregolarità scrittoria; l'ultima (XXXII) è lasciata allo stato di abbozzo, senza neppure l'apposizione del numero d'ordine. La fascicolazione di questa parte del codice è del resto irregolare, a differenza di quanto avviene per le sezioni precedenti e immediatamente seguenti, e la miglior spiegazione a questa irregolarità si può trovare proprio in una progressiva crescita del contenuto ${ }^{26}$. Tutto fa pensare perciò che materiale ulteriore venisse

25. Beda Venerabilis, In Regum librum XXX quaestiones, ed. D. Hurst, Turnhout 1967 (CCSL 119), pp. 293-322.

26. La sezione del manoscritto relativa ai Re, comprendente le Quaestiones di Beda e le Sententiae, costituisce il quinto fascicolo del manoscritto, che occupa le pp. 65-84. I quattro fascicoli precedenti sono regolari quaternioni e comprendono il commentario all'Ettateuco di Isidoro, che si conclude a metà della prima colonna della p. 63; il resto della p. 63 e la p. 64 erano state lidsciate bianche (solo in seguito vi è stato trascritto un testo agiografico). Il commen 6 sa Re, che inizia in capo alla p. 65, apre dunque anche da un punto di vista cödicelosesces una nuova sezione. Il quinto fascicolo

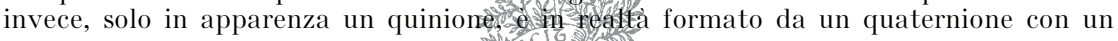

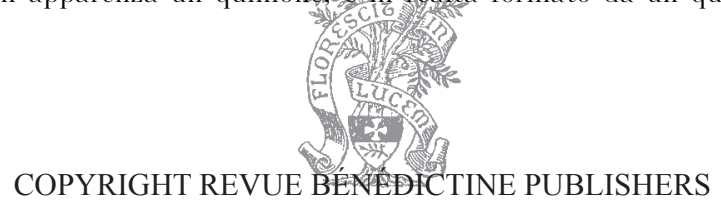


progressivamente unito a quello preesistente - cosa che la struttura in sententiae consentiva senza particolari problemi, ma che non sarebbe stata ammessa da un commentario perpetuo -, e che gli spezzoni esegetici già inclusi fossero considerati ulteriormente incrementabili.

I 32 estratti sono ricavati dalle seguenti opere ${ }^{27}$ :

\begin{tabular}{|l|l|l|l|}
\hline I & I Re, 6, 10-12 & $\begin{array}{l}\text { Gregorio Magno, Moralia (CPL } \\
1708), 7,42\end{array}$ & CCSL 143, 366,100-367,121 \\
\hline II & I Re, 15, 11.35 & $\begin{array}{l}\text { Eucherio, Instructiones (CPL } \\
\text { 489), Reg. II }\end{array}$ & CCSL 66, 103,436-104,439 \\
\hline III & I Re, 16, 15 & Eucherio, Instructiones, Reg. III & CCSL 66, 104,440-445 \\
\hline IV & I Re, 28, 8 & Eucherio, Instructiones, Reg. V & CCSL 66, 104,453-105,458 \\
\hline V & IV Re, 20,6 & $\begin{array}{l}\text { Eucherio, Instructiones, Reg. VI + } \\
\text { Gregorio Magno, Moralia, 12, 2 }\end{array}$ & $\begin{array}{l}\text { CCSL 66, 105,459-464 } \\
\text { CCSL 143A, 629,9-23 }\end{array}$ \\
\hline VI & I Re, 17, 17-18 & $\begin{array}{l}\text { Cesario di Arles, Sermones (CPL } \\
\text { 1008), 121 }\end{array}$ & CCSL 103, 505-508 \\
\hline
\end{tabular}

foglio singolo inserito dopo il sesto e un altro singolo incollato alla fine (i fogli "irregolari' o 'isolati' sono dunque quelli delle pp. 77-78 e 83-84). Nel fascicolo, le Quaestiones di Beda proseguono fino a occupare quasi tutta la prima colonna della p. 75, e sono seguite immediatamente dall'Incipit delle Sententiae; all'Incipit segue il sommario, che si interrompe a metà della seconda colonna della p. 75 , per il resto lasciata in bianco. Alla cima della p. 76 inizia il testo delle Sententiae, che prosegue poi fino a metà della seconda colonna della p. 83; la parte successiva di questa pagina e l'intera p. 84 sono rimaste bianche; in capo della p. 85 inizia il commentario successivo (Girolamo a Isaia), su un nuovo fascicolo che è regolarmente un quaternione (pp. 85-100). Considerando che la sententia XXIV, l'ultima per la quale la copiatura del testo e del sommario risulti regolare, si trova sulla p. 81, la spiegazione più semplice alle irregolarità nella composizione del quinto fascicolo è che si fosse inizialmente misurata una necessità di nove fogli (pp. 65-82) per copiare i due commentari ai Re, il secondo dei quali terminava appunto alla sententia XXIV, e che a tal fine il quaternione canonico fosse stato integrato con il primo foglio aggiuntivo (pp. 77-78); ma che in seguito, crescendo il commentario, sia stato necessario aggiungere anche le pp. 83-84. Se il ragionamento è esatto, se ne ricava che le Sententiae originarie comprendevano 24 unità.

27. Si riproduce qui, con qualche completamento e correzione ed evidenziando il rapporto dei singoli estratti con il sommario iniziale, l'elenco presentato da Gorman (pp. 296-300). Per il confronto si è fatto ricorso alle seguenti edizioni : Maximi episcoPI Taurinensis Sermones, ed. A. Mutzenbecher, Turnhout 1962 (CCSL 23); Sancti Caesari Arelatensis Sermones, I, ed. G. Morin, Turnhout 1953 (CCSL 103); Eucherit Lugdunensis Opera, ed. C. Mandolfo, I, Turnhout 2004 (CCSL 66); S. Gregoril Magni, Moralia in Iob, ed. M. Adriaen, I-III, Turnhout 1979-85 (CCSL 143, 143A, 143B); Grégoire le Grand, Régle pastorale, introduction, notes et index par B. Judic, texte critique par F. Rommel, traduction par Ch. Morel, Paris 1992 (Sources chrétiennes 381-382); Sancti Gregori Magni Homiliae in Hiezechielem prophetam, ed. M. Adriaen, Turnhout 1971 (CCSL 142); Beda, Opera, II : Opera exegetica, 3, ed. D. H. Hurst, Turnhout 1960 (CCSL 120) (In Lucam); Beda, Opera, II : Opera exegetica, IV, ed. D. H. Hurst, Turnhout 1983 (CCSL 121) (In Iacobum); S. HieroNymi presbyteri Opera, I : Opera exegetica, 6 , Commentarii in prophetas minores, ed. M. Adriaen, Turnhout 1970 (CCSL 76A); SHeronym presbyteri Tractatus sive Homiliae in Psalmos, ed. G. Morin, Tulbnhoul 1958 (CCSL 78); Origenes, Werke, VIII, ed. W. A. Bathrens, Leipzig 1925 (Gids 33

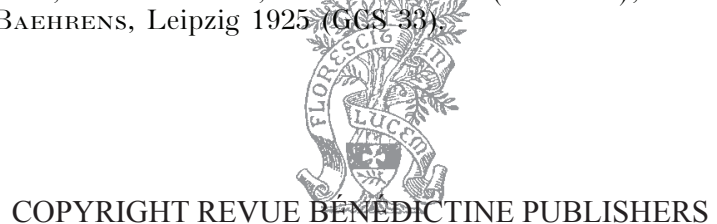




\begin{tabular}{|c|c|c|c|}
\hline VII & I Re, 16,23 & $\begin{array}{l}\text { Gregorio Magno, Regula Pastora- } \\
\text { lis (CPL 1712), } 26\end{array}$ & SC $382,270,50-272-66$ \\
\hline VIII & I Re, 17,49 & Gregorio Magno, Moralia, 18, 24 & $\begin{array}{l}\text { CCSL 143A, 900,21-901,29 } \\
\end{array}$ \\
\hline IX & II Re, $1,17-21$ & $\begin{array}{l}\text { Gregorio Magno, Moralia, } 4 \text {, } \\
\text { praef. } 4\end{array}$ & CCSL $143,161,114-129$ \\
\hline $\mathrm{X}$ & I Re, 15,17 & Gregorio Magno, Moralia, 34, 42 & CCSL 143B, 1763,15-35 \\
\hline $\mathrm{XI}$ & I Re, $15,22-23$ & Gregorio Magno, Moralia, 35, 28 & CCSL 143B, 1792,141-1793,152 \\
\hline XII & II Re, $4,5-6$ & Gregorio Magno, Moralia, 1, 50 & CCSL $143,51,29-52,48$ \\
\hline XIII & II Re, 6, 6-7 & Gregorio Magno, Moralia, 5, 24 & CCSL $143,234,167-235,196$ \\
\hline XIV & II Re, 11,2 & Gregorio Magno, Moralia, 3, 55 & CSL $143,148,21-149,57$ \\
\hline $\mathrm{XV}$ & II Re, $24,16-25$ & Cesario di Arles, Sermones, 122 & CCSL $103,510-511$ \\
\hline $\mathrm{XVI}$ & III Re, $3,16-27$ & $\begin{array}{l}\text { Massimo di Torino, Sermones } \\
(\text { CPL 219 A), } 52\end{array}$ & $\begin{array}{l}\text { CCSL 23, 210,14-15.23-34; } \\
211,37-39\end{array}$ \\
\hline XVII & III Re, 6,7 & Gregorio Magno, Moralia, 34, 23 & CCSL 143B, 1748,17-1749,34 \\
\hline XVIII & IV Re, 4,35 & Gregorio Magno, Moralia, 35, 18 & CCSL 143B, 1785, 166-169 \\
\hline XIX & IV Re, 5 & Cesario di Arles, Sermones, 129 & CCSL 103, 531-534 \\
\hline $\mathrm{XX}$ & I Re, 24,4 & $\begin{array}{l}\text { Girolamo, De psalmis (CPL 582), } \\
141+ \\
\text { Gregorio Magno, Regula Pastora- } \\
\text { lis, } 28\end{array}$ & $\begin{array}{l}\text { CCSL } 78,309,7-16 \\
\text { SC } 382,280,82-282,110\end{array}$ \\
\hline XXI & IV Re, $6,5-6$ & Gregorio Magno, Moralia, 22, 9 & CCSL 143A, 1098,30-1099,64 \\
\hline XXII & I Re, 30, 11-13 & Gregorio Magno, Moralia, 5, 73 & CCSL $143,272,13-28$ \\
\hline XXIII & III Re, 19,11 & Gregorio Magno, Moralia, 5, 66 & CCSL $143,265,37-266,76$ \\
\hline XXIV & III Re, 8,19 & Gregorio Magno, Moralia, 7, 56 & CCSL $143,377,12-19$ \\
\hline $\mathrm{XXV}^{*}$ & I Mac, $6,43-46$ & Gregorio Magno, Moralia, 19, 34 & CCSL $143 \mathrm{~A}, 983,49-54$ \\
\hline XXVI* & III Re, 10, 1-13 & $\begin{array}{l}\text { Origene, In Canticum (CPG } \\
\text { 1433), II }\end{array}$ & $\begin{array}{l}\text { GCS 33, 119,6-121,17; } 121,25- \\
122,10\end{array}$ \\
\hline XXVII* & IV Re, $4,1-7$ & $\begin{array}{l}\text { Gregorio Magno, Homeliae in } \\
\text { Hiezechihelem (CPL 1710), I, 3, } 6\end{array}$ & CCSL $142,36,109-124$ \\
\hline XXVIII* & I Re, $14,27.43$ & Massimo di Torino, Sermones, 69 & CCSL 23, 290,95-291,99 \\
\hline XXIX** & I Re, $17,34-37$ & $\begin{array}{l}\text { Girolamo, In Naum (CPL 589), } \\
\text { II, } 12\end{array}$ & CCSL 76A, 552,385-387 \\
\hline $\mathrm{XXX}^{* *}$ & III Re, 21 & $\begin{array}{l}\text { Beda, In epistolam Iacobi (CPL } \\
\text { 1362), I, } 11\end{array}$ & CCSL $121,186,123-127$ \\
\hline $\mathrm{XXXI}^{* *}$ & III Re, 17 & $\begin{array}{l}\text { Beda, In Lucam (CPL 1356), IV, } \\
25-27\end{array}$ & $\begin{array}{l}\text { CCSL } 120,106,258-108,332 \\
\end{array}$ \\
\hline (s.n.) & III Re, $1,1-4$ & Girolamo, Epistolae (CPL 620), 52 & $\begin{array}{l}\text { CSEL } 54,414,17-415,3 ; 416,1- \\
13\end{array}$ \\
\hline
\end{tabular}

* numero aggiunto in un secondo tempo nel sommario

** numero non presente nel sommario

Mentre le ultime sententiae della serie (dalla XXV in poi) riproducono una varietà di fonti e non sembrano seguire un ordine perspicuo - come si addice appunto a estratti aggiuntivi, progressivamente inseriti in una lista lasciata aperta sulla base di più recenti letture e ritrovamenti - , quello che in base all'indagine codicologica ${ }^{28}$

28. Vedi sopra, nota 26. 
sembrerebbe essere il corpo originario dell'opera (I-XXIV) appare più organico e definito. In questa sezione il compilatore utilizza soprattutto opere di Gregorio Magno - in modo preponderante i Moralia, occasionalmente la Regula - e in linea secondaria le omelie di Massimo di Torino e di Cesario di Arles, il commento di Girolamo ai Salmi e le Instructiones di Eucherio di Lione (di cui vengono riportate in blocco quattro quaestiones). L'ordine delle sententiae segue approssimativamente la successione del testo biblico, almeno fino alla $\mathrm{XIX}^{29}$ : fino a quel punto non si tratta perciò di semplice accumulo progressivo di materiali, ma di loro disposizione razionale.

Per le parti gregoriane, l'opinione di Gorman è che il compilatore di questo commentario attinga non direttamente alle opere del pontefice, bensi ai precedenti estratti che costituiscono il Liber testimoniorum di Paterio. E vero che nella maggior parte dei casi il commento di Gregorio accolto nel Parigino lat. 15679 si ritrova anche all'interno della raccolta pateriana; ma tale circostanza sembra doversi imputare semplicemente all'analogia delle operazioni compiute per la costituzione del Liber testimoniorum di Paterio e delle Sententiae, e non a una dipendenza delle seconde dal primo. In realtà solo per le sententiae XII e XXII l'estratto gregoriano che si incontra nel manoscritto Parigino coincide esattamente con quello riportato da Paterio ${ }^{30}$; in tutti gli altri casi vi sono divergenze di estensione, di solito perché l'estratto pateriano è più ampio di quello riferito dal Parigino ${ }^{31}$, ma talvolta anche perché è l'estratto del Parigino a riportare dell'opera gregoriana qualche frase in più ${ }^{32}$. Interessante è il caso della prima delle Sententiae, che commenta il passo I Re 6, 10-12, sul quale Gregorio era intervenuto due volte in due diverse sue opere (Moralia 7, 42; Homiliae in Evangelia 37, 4) ${ }^{33}$. A questo passo biblico aveva riservato una scheda anche Paterio, che, qui come altrove, aveva fuso le parti che ricavava dalle due opere di Gregorio in una trattazione unitaria.

29. La successione è solo apparentemente interrotta nel caso degli estratti da Eucherio, che come si è detto sono riportati in blocco.

30. Il testo del Liber testimoniorum di Paterio pubblicato dalla PL (cfr. nota 14) è stato da noi ricontrollato, per i passi in questione, sul manoscritto Parigino n.a.l. 1597, degli ultimi decenni dell'VIII sec., che - insieme al codice Amiens, Bibliothèque Municipale 220 - costituisce il più antico testimone segnalato dell'opera; su questo codice cfr. più oltre, nota 93. Il controllo ha confermato nella sostanza, per quanto di interesse del presente articolo, il testo pubblicato dai Maurini.

31. Cosa che avviene per le sententiae $7,8,9,10,11,13,14,17,20,21$.

32. Cosa che avviene per le sententiae 7, 21, 23.

33. Per le Homeliae in Evangelia si è fatte ficónso all'edizione di R. Étaix, Gregorius Magnus, Homiliae in Evangelia, Tutromer1969 (CCSL 141). In questa edizione il passo citato si legge alle pp. 350-1.

RB 18

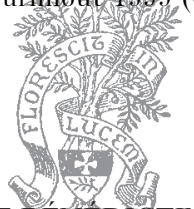


La sententia del Parigino corrisponde invece al commento del passo biblico che Gregorio aveva dato nei soli Moralia; se l'epitomatore avesse attinto al Liber testimoniorum, sarebbe stato insensato - e probabilmente anche impossibile - ripristinare la sola parte relativa ai Moralia, eliminando quanto proveniva dalle Homeliae. Si vedano i tre passi in parallelo ${ }^{34}$ :

\begin{tabular}{|c|c|c|}
\hline $\begin{array}{c}\text { Moralia 7, } 42 \\
\text { (GGSL 143, 366-7) }\end{array}$ & Paterio (PL 79, 791 A-G) & $\begin{array}{l}\text { Sententiae in Regum } \\
\text { (Par. lat. 15679), p. } 76\end{array}$ \\
\hline $\begin{array}{l}\text { Tollentes duas uaccas quae } \\
\text { lactabant uitulos iunxerunt } \\
\text { ad plaustrum, uitulosque ea- } \\
\text { rum clauserunt domi et po- } \\
\text { suerunt arcam Dei super } \\
\text { plaustrum. Et paulo post: } \\
\text { Ibant in directum uaccae per } \\
\text { uiam quae ducit Bethsames, } \\
\text { et itinere uno gradiebantur, } \\
\text { pergentes et mugientes, }\end{array}$ & $\begin{array}{l}\text { IN Expositione IN Evange- } \\
\text { Lia Onelia XXVII. Cum de } \\
\text { discretae compassionis bono } \\
\text { proximis exhibendo tractare- } \\
\text { tur, adiunctum est: } \\
\text { Tollentes duas uaccas quae } \\
\text { lactabant uitulos iunxerunt } \\
\text { ad plaustrum, uitulosque ea- } \\
\text { rum clauserunt domi et po- } \\
\text { suerunt arcam Dei super } \\
\text { plaustrum. Et paulo post: } \\
\text { Ibant in directum uaccae per } \\
\text { uiam quae ducit Bethsamis } \\
\text { pergentes et mugientes. } \\
\text { Cum de terra Philistiim arca } \\
\text { Domini ad terram Israelitarum } \\
\text { rediret, plaustro superimposita } \\
\text { est et uaccae plaustro subiunc- } \\
\text { tae sunt, quae fetae fuisse me- } \\
\text { morantur. Quarum filios } \\
\text { clauserunt domi. Et scriplum } \\
\text { est: Ibant autem in directum } \\
\text { uaccae per uiam quam ducit } \\
\text { Bethsamis, uno itinere gradie- } \\
\text { bantur pergentes et mugientes } \\
\text { et non declinabant neque ad } \\
\text { dexteram neque ad sinistram. }\end{array}$ & $\begin{array}{l}\text { Tollentes duas uaccas quae } \\
\text { lactabant uitulos iunxerunt } \\
\text { ad plaustrum, uitulosque ea- } \\
\text { rum clauserunt domi et po- } \\
\text { suerunt arcam Dei super } \\
\text { plaustrum. Et paulo post: } \\
\text { Ibant in directum uaccae per } \\
\text { uiam quae ducit Bethsamis, } \\
\text { et itinere uno gradiebantur, } \\
\text { pergentes et mugientes, }\end{array}$ \\
\hline
\end{tabular}

34. La trascrizione delle Sententiae rispetta la forma del manoscritto, con qualche uniformazione ortografica, la sistemazione di piccoli ma palesi errori di copia e l'aggiunta di una punteggiatura moderna; quella dei Moralia riproduce l'edizione Adriaen, anche in questo caso con qualche uniformazione ortografica e di punteggiatura; quella di Paterio riprende l'edizione dei Maurini, sempre con qualche uniformazione, ma in aggiunta in qualche punto il testo è stato tacitamente rettificato sulla base del manoscritto Parigino n.a.l. 1597 (ff. 87v-88r). La collazione con questo codice conferma comunque nella sostanza, per questa parte, il testo dei Maurini. In carattere corsivo è riportata la sezione che Paterio ricava dêles Homiliae in Evangelia; in tondo quanto deriva dai Moralia; in neretto un brâtese te Whalia che si trova in posizione diversa nella scheda pateriana. 


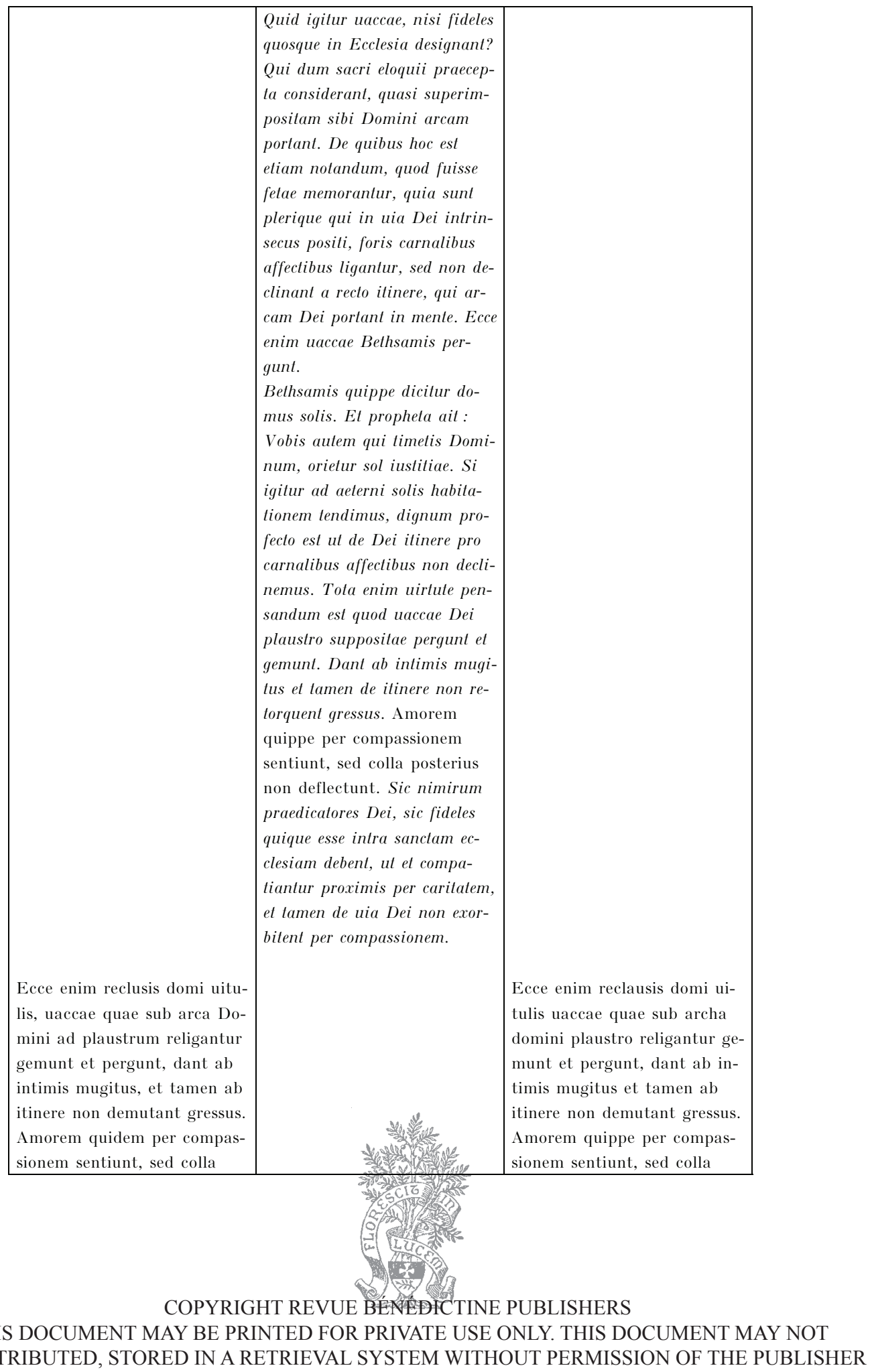




\begin{tabular}{|c|c|c|}
\hline $\begin{array}{l}\text { posterius non deflectunt. } \\
\text { Sic, sic necesse est ut in- } \\
\text { cedere debeant qui, sacrae } \\
\text { legis iugo suppositi, iam } \\
\text { per internam scientiam } \\
\text { Domini arcam portant, } \\
\text { quatenus per hoc quod } \\
\text { propinquorum necessitati- } \\
\text { bus condolent a coepto } \\
\text { rectitudinis itinere non } \\
\text { declinent. } \\
\text { Bethsames quippe domus so- } \\
\text { lis dicitur. } \\
\text { Arca ergo Domini superposita } \\
\text { Bethsames pergere est cum } \\
\text { superna scientia ad aeternae } \\
\text { lucis habitaculum propin- } \\
\text { quare. Sed tunc uere Bethsa- } \\
\text { mes tendimus, cum uiam } \\
\text { rectitudinis gradientes ad ui- } \\
\text { cina erroris latera nec pro af- } \\
\text { fectu pignorum declinamus. }\end{array}$ & $\begin{array}{l}\text { Arca quippe superimposita } \\
\text { Bethsamis pergere est cum } \\
\text { superna scientia ad aeternae } \\
\text { lucis habitaculum propin- } \\
\text { quare. Sed tunc uere Bethsa- } \\
\text { mis tendimus, cum uiam } \\
\text { rectitudinis gradientes ad ui- } \\
\text { cina erroris latera nec pro af- } \\
\text { fectu pignorum declinamus. } \\
\text { Sic namque, sic necesse } \\
\text { est ut incedere debeant, } \\
\text { qui sacrae legis iugo sup- } \\
\text { positi, iam per internam } \\
\text { scientiam Dei arcam por- } \\
\text { tant, quatenus per hoc } \\
\text { quod propinquorum ne- } \\
\text { cessitatibus condolent, a } \\
\text { coepto rectitudinis itinere } \\
\text { non declinent. } \\
\text { Quorum nimirum gratia men- } \\
\text { tem nostram tenere debet, sed } \\
\text { reflectere non debet, ne haec } \\
\text { eadem mens aut si affectu } \\
\text { non tangitur dura sit, aut } \\
\text { plus tacta, si inflectitur, re- } \\
\text { missa. }\end{array}$ & $\begin{array}{l}\text { Bethsamis quippe domus solis } \\
\text { dicitur. } \\
\text { Archa ergo superposita Beth- } \\
\text { samis pergere est cum super- } \\
\text { na scientia ad internae lucis } \\
\text { habitaculum propinquare. Sed } \\
\text { tunc uere Bethsamis tendi- } \\
\text { mus, cum uiam rectitudinis } \\
\text { gradientes ad uicina erroris } \\
\text { latera nec pro affectu pigne- } \\
\text { rum declinamus. }\end{array}$ \\
\hline
\end{tabular}

Citiamo anche il caso della sententia VII, dove a commento di I Re 16, 23 viene riportato un brano della Regula pastoralis. Tale brano è presente anche nel Liber testimoniorum, dove figurano però una sezione in più e una in meno: 


\begin{tabular}{|c|c|c|}
\hline $\begin{array}{l}\text { Regula pastoralis, } 26 \\
\quad \text { (SG 381, 270-2) }\end{array}$ & Paterio (PL 79, 795 G-D) & $\begin{array}{c}\text { Sententiae in Regum, } \\
\text { (Par. lat. 15679), p. } 77^{35}\end{array}$ \\
\hline $\begin{array}{l}\text { Nonnunquam tamen etiam } \\
\text { superbus diues exhortationis } \\
\text { blandimento placandus est, } \\
\text { quia et plerumque dura uul- } \\
\text { nera per lenia fomenta mol- } \\
\text { lescunt, et furor insanorum } \\
\text { saepe ad salutem medico } \\
\text { blandiente reducitur; cumque } \\
\text { eis in dulcedine condescendi- } \\
\text { tur, languor insaniae mitiga- } \\
\text { tur. Neque enim neglegenter } \\
\text { intuendum est, quod cum } \\
\text { Saulem spiritus aduersus } \\
\text { inuaderet, apprehensa Dauid } \\
\text { cithara, eius uesaniam seda- } \\
\text { bat. Quid enim per Saulem, } \\
\text { nisi elatio potentium; et quid } \\
\text { per Dauid innuitur, nisi hu- } \\
\text { milis uita sanctorum? Cum } \\
\text { ergo Saul ab immundo spiritu } \\
\text { arripitur, Dauid canente, eius } \\
\text { uesania temperatur; quia cum } \\
\text { sensus potentium per elatio- } \\
\text { nem in furorem uertitur, di- } \\
\text { gnum est, ut ad salutem } \\
\text { mentis quasi dulcedine citha- } \\
\text { rae, loquutionis nostrae tran- } \\
\text { quillitate reuocetur. Ali- } \\
\text { quando autem cum huius } \\
\text { saeculi potentes arguuntur, } \\
\text { prius per quasdam similitudi- } \\
\text { nes uelut de alieno negotio } \\
\text { requirendi sunt; et cum rec- } \\
\text { tam sententiam quasi in alte- } \\
\text { rum protulerint, tunc modis } \\
\text { congruentibus de proprio rea- } \\
\text { tu feriendi; ut mens tempora- } \\
\text { li potentia tumida contra } \\
\text { corripientem nequaquam se } \\
\text { erigat, quae suo sibi iudicio } \\
\text { superbiae ceruicem calcat; et }\end{array}$ & $\begin{array}{l}\text { Plerumque superbus diues ex- } \\
\text { hortationis blandimento pla- } \\
\text { candus est, quia et plerumque } \\
\text { dura uulnera per lenia fomen- } \\
\text { ta mollescunt, et furor insa- } \\
\text { norum saepe ad salutem } \\
\text { medico blandiente reducitur; } \\
\text { cumque eis in dulcedine } \\
\text { condescenditur, languor insa- } \\
\text { niae mitigatur. Neque enim } \\
\text { neglegenter intuendum est } \\
\text { quod cum Saulem spiritus } \\
\text { aduersus inuaderet, apprehen- } \\
\text { sa Dauid cithara eius uesa- } \\
\text { niam sedabat. Quid enim per } \\
\text { Saulem nisi elatio potentium, } \\
\text { et quid per Dauid innuitur } \\
\text { nisi humilis uita sanctorum? } \\
\text { Cum ergo Saul ab immundo } \\
\text { spiritu arripitur, Dauid ca- } \\
\text { nente, eius uesania tempera- } \\
\text { tur, quia cum sensus } \\
\text { potentium per elationem in } \\
\text { furorem uertitur, dignum est } \\
\text { ut ad salutem mentis quasi ad } \\
\text { dulcedinem citharae locutio- } \\
\text { nis nostrae tranquillitate } \\
\text { reuocetur. }\end{array}$ & 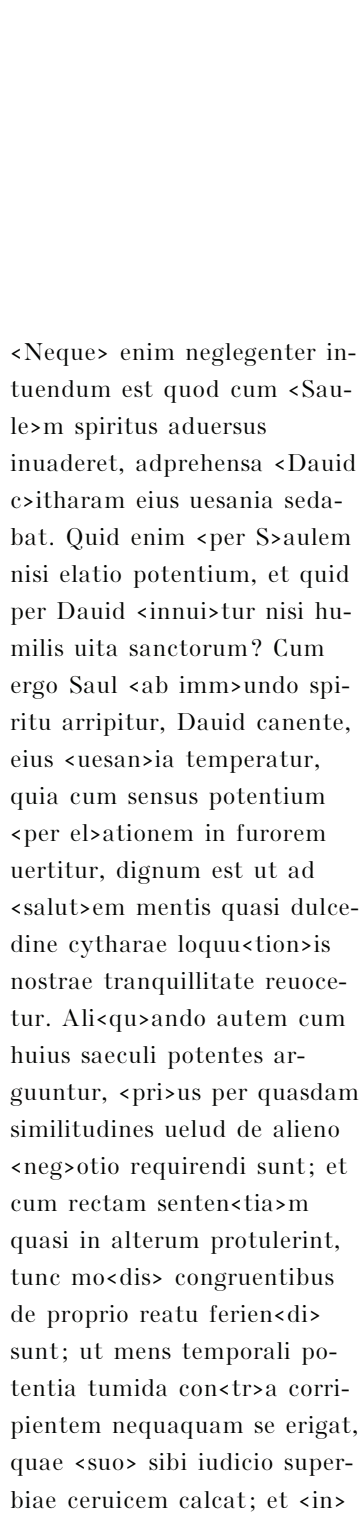 \\
\hline
\end{tabular}

35. Il margine sinistro del foglio è illeggibilex he integrazioni vengono indicate con la parentesi uncinata. 


\begin{tabular}{|l|l|l|}
\hline $\begin{array}{l}\text { in nulla sui defensione se } \\
\text { exerceat, quam sententia pro- } \\
\text { prii oris ligat. }\end{array}$ & $\begin{array}{l}\text { nulla sui defensione se exer- } \\
\text { ceat, quam <sente>ntia pro- } \\
\text { prii oris ligat. }\end{array}$ \\
\hline
\end{tabular}

Si può ancora aggiungere che la sententia XVIII corrisponde a un brano gregoriano non riportato da Paterio ${ }^{36}$; cosi come al contrario sono molti i brani di Gregorio riportati da Paterio che non sono compresi nelle Sententiae. Bisognerà concludere che le Sententiae attingono ai Moralia e alla Regula pastoralis direttamente, e non attraverso la mediazione di Paterio; anche se non si può escludere che il Liber testimoniorum, con l'esplicita indicazione che forniva della citazione gregoriana, abbia costituito comunque un sussidio al lavoro. Identico a quello di Paterio, in ogni caso, è il metodo: vengono ricavati estratti dai testimonia biblici delle auctoritates consultate, e tali estratti sono poi disposti (con qualche approssimazione) nell'ordine narrativo del testo biblico.

E' quanto mai probabile che le Sententiae siano preesistenti al codice Parigino, così come lo sono la maggior parte degli altri commentari che vi sono raccolti : per la sua compilazione Teodolfo non componeva di preferenza nuovi trattati esegetici, ma selezionava piuttosto i più adatti fra quelli disponibili, spesso sottoponendoli a revisioni e riduzioni, e li collocava poi in serie continua. Un aspetto della revisione e del riutilizzo potrebbe essere appunto il fatto di avere lasciato 'aperto' il testo, in modo da consentirne ulteriori incrementi ${ }^{37}$.

Le fonti utilizzate dal compilatore - oltre a Gregorio, come si è detto, Cesario di Arles, Massimo di Torino, Eucherio di Lione e Girolamo - sono testi piuttosto diffusi nell'alto medioevo occidentale, tanto da non poter fornire in prima battuta elementi utili all'individuazione di un ambiente di produzione. La presenza di due scrittori della Francia centro-meridionale come Cesario ed Eucherio potrebbe indirizzare verso questo territorio; ma come elemento isolato ha peso assai modesto. Più interessante è il fatto che i sermoni di Cesario, soprattutto il 129, si leggano nell'epitome del Parigino lat. 15679 con delle differenze rispetto alla vulgata $^{38}$ : potrebbe trattarsi

36. Invece la sententia 25 si trova in Paterio, ma come commento secondario a un passo del Genesi (PL 79, 689C).

37. Il fatto che i passi dei Re commentati da Beda nelle Quaestiones siano tutti diversi da quelli commentati nelle Sententide risale alla fonte : i passi presi in considerazione da Gregorio, che costituisce la fonteremota principale delle Sententiae, erano

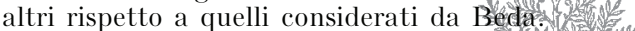

38. Cioè all'edizione Morin (CCSL 103)

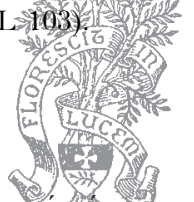


di rielaborazione dell'epitomatore, caratterizzata in particolare dall'eliminazione di alcune frasi superflue ${ }^{39}$, o potrebbe essere stata qui recuperata una particolare forma redazionale dell'opera. Gli studi sulla tradizione dei sermoni di Cesario sono tuttavia troppo arretrati perché se ne possa ricavare qualunque indicazione di ordine filologico; il che vale del resto anche per le altre opere utilizzate, per le quali non si possono invocare le (del resto rare) varianti rispetto alla forma vulgata per individuare parentele o affinità con testimoni esterni.

La differenza delle fonti utilizzate dalle Sententiae rispetto a quelle degli altri commentatori carolingi dei libri dei Re è notevole. Per redigere il suo commentario Claudio di Torino impiega varie opere di Agostino, le Quaestiones e il De templo Salomonis di Beda, le Quaestiones in Vetus Testamentum di Isidoro, un'omelia di Origene e una di Giovanni Crisostomo; e inoltre due sermoni di Cesario di Arles - uno dei quali è usato anche nel Parigino lat. 15679 - e il Liber testimoniorum di Paterio ${ }^{40}$. Rabano Mauro utilizza in parte queste stesse opere, ma vi aggiunge informazioni tratte dalle Antiquitates di Giuseppe Flavio, dal De situ et nominibus locorum Hebraicorum di Girolamo e dalle Quaestiones Hebraicae in Samuhelem; mentre il commento di Angelomo di Luxeuil, che riprende in larga misura quello di Rabano, lo integra con nuove notizie tratte da Isidoro, Beda, Paterio, ancora dalle Quaestiones Hebraicae in Samuhelem e direttamente dai Moralia $^{41}$. Nelle Sententiae del Parigino lat. 15679 la fonte prevalente è invece Gregorio, autore in apparenza meno utilizzato dagli altri commentatori dell'epoca. La coincidenza con quanto dice del suo precedente lavoro il compilatore dell'Epitome Marrier (" in Regnorum libro aggregatis omnibus patrum sententiis, maxime autem sanctissimi papae Gregorii, ... coniunxi libellum ») è evidente, ed è più significativa in quanto delinea una situazione per l'epoca non molto consueta; così come coincidente è la definizione che l'autore dà del suo lavoro sui Re come raccolta di sententiae, e non come commentario continuo, né come discussione di quaestiones. Inoltre, la prevalenza delle citazioni dai Moralia nelle Sententiae del codice Parigino implica che l'autore di esse abbia grande familiarità

39. Per gli altri testi tuttavia l'epitomatore non ricorre a simili espedienti.

40. G. Italiani, La tradizione esegetica nel commento ai Re di Claudio di Torino, Firenze 1979. Sul commentario di Claudio cfr. anche M. M. Gorman, The Commentary on Kings of Claudius of Turin and its two Printed Editions (Basel, 1531; Bologna 1755), "Filologia mediolatina " 4 (1997), p1 10131 (ristampato in M. M. Gorman,

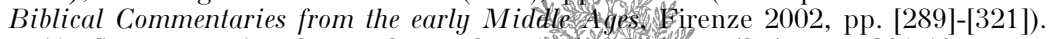

41. Cantelli, Angelomo e la scuola esegelina in hiveuil cit., pp. 301-10.

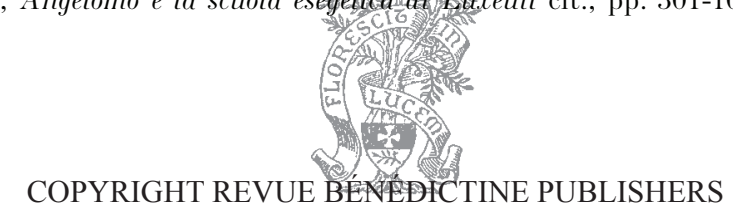


con questo testo, e ne abbia effettuato una lettura continua; la stessa azione - non certo scontata, data l'estensione dell'opera gregoriana che deve per forza di cosa avere effettuato il compilatore dell'Epitome Marrier. Senza che si possa arrivare a un'identificazione assolutamente certa, si può però almeno dire che fra tutti i commenti ai Re dell'alto medioevo finora noti l'unico che corrisponda alla descrizione del prologo dell'Epitome Marrier, e che abbia quindi qualche probabilità di identificarsi con esso, è quello che si incontra nella miscellanea di Teodolfo.

\section{Il doppio prologo dell'Epitome MarRier}

E il doppio prologo della Concordia Regularum

Le osservazioni che avevano portato Fidel Rädle a escludere per primo la paternità oddoniana dell'Epitome Marrier si leggono all'interno del suo studio sull'opera di Smaragdo di Saint-Mihiel, nella parte dedicata agli influssi visigotici sulla tecnica versificatoria di questo scrittore $^{42}$. Il secondo prologo dell'Epitome Marrier, quello scritto in esametri, sarebbe da annoverare, a giudizio di Rädle, in un gruppo di carmi che presenterebbe forti affinità con quelli di Smaragdo ${ }^{43}$, e che comprenderebbe anche il prologo alla Concordia Regularum di Benedetto di Aniane ${ }^{44}$, i componimenti conservati nel codice Parigino lat. 8812 (per i quali è stata ugualmente supposta un'origine ananiense) $)^{45}$, e quelli di Teodolfo di Orléans ${ }^{46}$. Tali affinità riguarderebbero tanto gli aspetti metrici e prosodici, quanto l’impiego di espressioni o stilemi comuni. A giudizio di Rädle, le affinità si spiegherebbero con il comune collegamento di tutti questi testi con il sostrato culturale visigotico : terra visigota era la Settimania, da dove proveniva Benedetto e dove si trovava Aniane; visigoto era Teodolfo di Orléans, il più celebre fra questi ecclesiastici; la tradizione visigota

42. RäDle, Studien zu Smaragd von Saint-Mihiel cit., pp. 39-51.

43. MGH, Poetae, I (ed. E. Dümmler), München 1881, pp. 605-19; quelli inseriti nel trattato grammaticale sono stati pubblicati più di recente in Smaragdi Liber in partibus Donati, edd. B. Löfstedt - L. Holtz - A. Kibre, Turnhout 1986 (CCCM 68).

44. Benedicti Ananiensis Concordia Regularum, ed. P. Bonnerue, Turnhout 1999 (CCCM 168-168A), II, pp. 5-7; in precedenza pubblicato in MGH, Poetae, VI,1 (ed. K. Strecker), München 1978, pp. 167-9.

45. Ibidem, pp. 135-41; A. Wilmart, Metres et rythmes carolingiens, "Archivum Latinitatis medii aevi " 15,2 (1940-41), pp. 105-211, alle pp. 195-204; il manoscritto è ricollegato da Wilmart all'insegnamento di A A do, il biografo di Benedetto di Aniane.

46. MGH, Poetae, I, cit., pp. 437-581

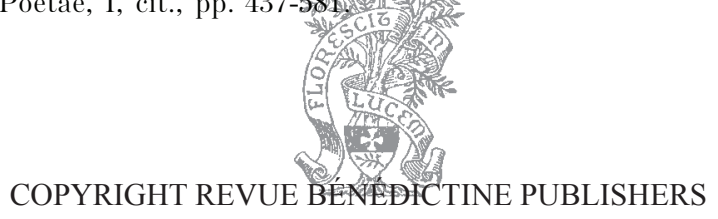


più antica - rappresentata dai carmi di Eugenio di Toledo ${ }^{47}$, dal breve prologo in versi al Liber sententiarum di Taione di Saragozza ${ }^{48}$ e dalla serie di componimenti di esortazione a un principe attribuiti a Smaragdo da Wilhelm Meyer, ma considerati da Rädle di due secoli più antichi e di area iberica ${ }^{49}$ — sarebbe riecheggiata nelle poesie del gruppo; con ogni probabilità visigoto, e comunque dall'ambiente visigoto fortemente influenzato, risulta infine Smaragdo ${ }^{50}$. Anche l'Epitome Marrier andrebbe dunque per Rädle attribuita a questo ambiente di tradizione visigotica; un ambiente tuttavia "zeitlich nicht eng begrenzt ", visto che le caratteristiche formali degli scrittori visigotici del VII secolo non parrebbero differenziarsi molto da quelle degli scrittori del IX, e che si estenderebbe dunque senza distinzioni evidenti dall'epoca di Taione a quella di Smaragdo.

Rädle registra un congruo numero di stilemi ed espressioni comuni fra il prologo dell'Epitome Marrier e gli altri componimenti poetici di cui abbiamo parlato. Con i Carmina Ananiensia i parallelismi sono i seguenti :

\begin{tabular}{|c|c|}
\hline Epitome Marrier & Carmen Ananiense I \\
\hline $\begin{array}{l}\text { Historiam Iobab, cuius per compita mundi } \\
\text { Laus ueneranda nitet, quadro quem climate } \\
\text { tensa } \\
\text { Aecclesia reboans laudat, hunc arbiter ipse } \\
\text { (vv. 25-7) }\end{array}$ & $\begin{array}{l}\text { O veneranda dies celebrat quam climate } \\
\text { Ecclessia quadro toto de corde per euum } \\
\text { (vv. 18-9) } \\
\text { Concrepet omnis in excelso per compita } \\
\text { mundi } \\
\text { Terra simul reboet, caelum, mare, sidera cuncta } \\
\text { (vv. 35-6) }\end{array}$ \\
\hline $\begin{array}{l}\text { Quae norunt nimium et duras mollescere } \\
\text { mentes, } \\
\text { Lumine praeclaro et tenebras depellere } \\
\text { tetras (vv. } 4-5)\end{array}$ & $\begin{array}{l}\text { Pellere quae norit tetras de corde tenebras } \\
\text { (v. 49) }\end{array}$ \\
\hline
\end{tabular}

47. Eugenii Toletani Opera omnia, ed. P. F. Alberto, Turnhout 2005 (CCSL 114).

48. CPL 1268 (PL 80, 751-2). Utilizzato in seguito, con un'estensione finale, come prologo all'omeliario di Alano di Farfa (ed. K. Strecker, MGH, Poetae, VI,1, pp. 177-8).

49. W. Meyer, Smaragds Mahnbüchlein für einen Karolinger, «Nachrichten von der Gesellschaft der Wissenschaften zu Göttingen », Phil.-hist. Klasse, 1907, pp. 39-70; RäDle, Studien zu Smaragd von Saint-Mihiel eit., pp. 32-39.

50. Sull'origine visigotica di Smaragdo oftrage elementi riferiti da RäDle, Stu-

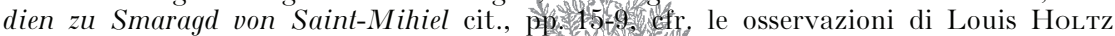
nell'introduzione a Smaragd Liber in paflowis 10 mati cit., pp. IX-XI. 
Con i versi di Smaragdo i seguenti :

\begin{tabular}{|c|c|}
\hline Epitome Marrier & Smaragdo, Carmina \\
\hline $\begin{array}{l}\text { Gregorii sancti nitidos percurrere campos } \\
\text { (v. 1) } \\
\text { Quis, ait, hos hominum poterit percurrere } \\
\text { campos (v. 43) }\end{array}$ & $\begin{array}{l}\text { Sic pariter nitidos norunt discurrere campos } \\
\ldots \\
\text { Adgrediar varios verbi discurrere campos } \\
(1,8,9) \\
\ldots \\
\text { Argenti nitidos distincto limite campos }(3,9)\end{array}$ \\
\hline Lucidior auro, uitro praeclarior omni (v. 8) & $\begin{array}{l}\text { Glarior argento fulvo praestantior auro } \\
\text { Dulcidior melle candidiorque nive, } \\
\text { Lucidior vitro, cristallo purior albo } \\
\qquad(1,9,19-21)\end{array}$ \\
\hline $\begin{array}{l}\text { Arbiter haec nouit superus qui sidera sentit } \\
\text { (v. 55) }\end{array}$ & $\begin{array}{r}\text { Arbiter ut tribuit caelo qui praesidet alto }(1,9, \\
25)\end{array}$ \\
\hline $\begin{array}{l}\text { Illa dapes tribuunt, nouit hoc porgere lacte } \\
\text { (v. 60) }\end{array}$ & Lactea cum solido pocula pane dabit $(1,1,34)$ \\
\hline
\end{tabular}

Con il prologo metrico della Concordia Regularum di Benedetto di Aniane i seguenti :

\begin{tabular}{|c|c|}
\hline Epitome Marrier & $\begin{array}{l}\text { Benedetto di Aniane, } \\
\text { Concordia Regularum }\end{array}$ \\
\hline $\begin{array}{l}\text { Vt coepi micuere quidem ceu sidera coeli } \\
\text { (v. 2) }\end{array}$ & $\begin{array}{l}\text { Multigenaeque simul micuere per aethera } \\
\text { stellae (v. 4) } \\
\ldots \\
\text { Expauere quidem rutilantia sidera caeli (v. 9) }\end{array}$ \\
\hline $\begin{array}{l}\text { Lumine praeclaro et tenebras depellere } \\
\qquad \text { tetras (v. 5) }\end{array}$ & $\begin{array}{l}\text { Arbiter ut mundi tenebras depelleret omnes } \\
\text { (v. 1) } \\
\text { Perdiderat gestans tetras in corde tenebras } \\
\text { (v. 11) } \\
\text { Has tamen ut tenebras superus discinderet } \\
\text { omnes (v. 14) }\end{array}$ \\
\hline $\begin{array}{l}\text { Cuius ab ore fluens fluuius per compita mundi } \\
\text { (v. } 6) \\
\text { Historiam Iobab, cuius per compita mundi } \\
\text { (v. 25) }\end{array}$ & $\begin{array}{l}\text { Coetus apostolicus reboans per compita } \\
\text { mundi (v. 19) }\end{array}$ \\
\hline $\begin{array}{l}\text { Mellifluo gustu cuncta redolentia uincens (v. 9) } \\
\text {... } \\
\text { Floribus aspersa redolent pulcherrima uisu } \\
\text { (v. 32) }\end{array}$ & $\begin{array}{l}\text { Ac uiolae fulgent, redolent uernantia quaeque } \\
\text { (v. 47) }\end{array}$ \\
\hline $\begin{array}{l}\text { O si mille forent doctae mihi milia linguae } \\
\text { (v. } 13 \text { ) }\end{array}$ & $\begin{array}{l}\text { Fecit amor sacrus, patuit post milia mille } \\
\text { (v. 23) }\end{array}$ \\
\hline
\end{tabular}

51. Questa occorrenza non è presentalle

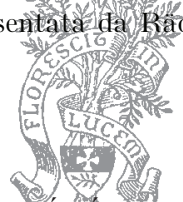




\begin{tabular}{|c|c|}
\hline $\begin{array}{l}\text { Aecclesia reboans laudat, hunc arbiter ipse } \\
\text { (v. 27) } \\
\begin{array}{l}\text { Arbiter haec nouit superus qui sidera sentit } \\
\text { (v. 55) }\end{array}\end{array}$ & 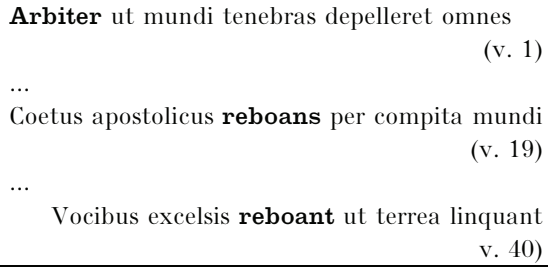 \\
\hline $\begin{array}{l}\text { Hinc etenim uiolae rutilant, hinc lilia } \\
\text { candent } \\
\text { Emicat hinc rosa, narcissus seu nardus, } \\
\text { amomum (vv. 33-4) }\end{array}$ & $\begin{array}{l}\text { In qua ualde rosae rutilant et lilia candent } \\
\text { (v. 44) } \\
\text { Ac uiolae fulgent, redolent uernantia quaeque } \\
\text { (v. 47) }\end{array}$ \\
\hline $\begin{array}{r}\text { Hos ego florigeros cupiens percurrere campos } \\
\text { (v. 36) }\end{array}$ & $\begin{array}{r}\text { Florigera ueluti monachis depingere serta } \\
\text { (v. 45) }\end{array}$ \\
\hline $\begin{array}{r}\text { Illa dapes tribuunt, nouit hoc porgere lacte } \\
\text { v. } 60)\end{array}$ & $\begin{array}{r}\text { Haec est uera uia, porgit haec pocula uitae } \\
\text { (v. 58) }\end{array}$ \\
\hline $\begin{array}{l}\text { Multigenosque mihi perpes decerpere flores } \\
\text { (v. 37) } \\
\begin{array}{l}\text {.. } \\
\text { Aut quis hos poterit flores decerpere } \\
\text { cunctos? (v. 44) }\end{array}\end{array}$ & $\begin{array}{l}\text { Ex quorum documentis hos decerpere flores } \\
\text { Multigenos placuit unoque scribere libro } \\
\text { (vv. 43-4) }\end{array}$ \\
\hline
\end{tabular}

Per completezza, indichiamo anche alcuni parallelismi, non segnalati da Rädle, che si possono riscontrare fra il prologo dell'Epitome Marrier e i componimenti di Teodolfo di Orléans :

\begin{tabular}{|c|c|}
\hline Epitome Marrier & Teodolfo di Orléans, Carmina \\
\hline $\begin{array}{l}\text { Cuius ab ore fluens fluuius per compita mundi } \\
\text { (v. } 6) \\
\text { Historiam Iobab cuius per compita mundi } \\
\text { (v. 25) }\end{array}$ & $\begin{array}{l}\text { Hoc euangelicus lituus per compita mundi } \\
\ldots \\
\text { Quattuor egregie reboant per compita mundi } \\
(28,19) \\
\ldots \\
\text { Haec tuba terribilis mugit per compita mundi } \\
(41,1,143)\end{array}$ \\
\hline $\begin{array}{l}\text { O si mille forent doctae mihi milia linguae, } \\
\text { Mille meumque sonos posset depromere } \\
\text { guttur, } \\
\text { Aerea uoxque mihi posset dare ferrea uerba } \\
\text { (vv. 13-5) }\end{array}$ & $\begin{array}{r}\text { Si mihi mille forent centeno in gutture } \\
\text { linguae } \\
\text { Aerea vox cunctis ferrea verba daret, } \\
\text { Non possem, fateor, tot promere sedis } \\
\text { amoenae } \\
\text { Gaudia quae capiunt qui bene iura tenent. } \\
(28,9-12)^{52}\end{array}$ \\
\hline
\end{tabular}

52. Il modello remoto è qui virgiliano (Non mihi si linguae centum sint oraque centum / ferrea uоx: Aen. VI, 625-6; Georg. II, 43-4), ma probabilmente filtrato da poeti cristiani tardoantichi (per esempio Sedulio, Carmen paschale I, 99-100: Non centum licet ora movens uox ferrea clamet / Centenosque sonos humanum pectus anhelet; o Alcimo Avito, Carmina III, 335-6 : Non cui uel centum finguae uel ferrea uox est / Enumerare

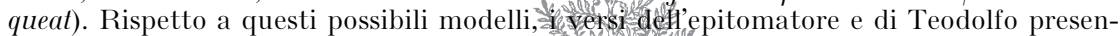

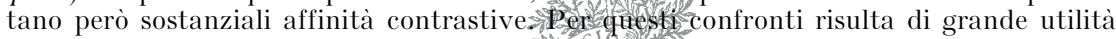

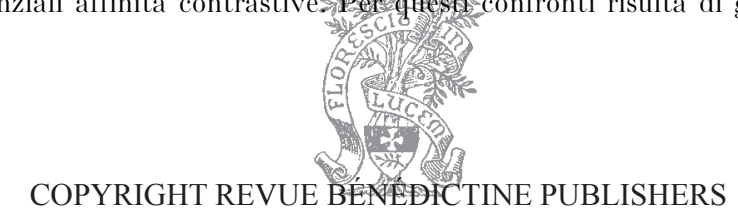




\begin{tabular}{|c|c|}
\hline $\begin{array}{r}\text { Illa dapes tribuunt, nouit hoc porgere lacte } \\
\text { v. } 60)\end{array}$ & $\begin{array}{l}\text { Discipulisque dapes tribuit, dant plebibus illi } \\
\qquad \begin{array}{l}(19,55) \\
\text { Hos solidis dapibus, hos ope lactis alit } \\
(41,1,182)\end{array}\end{array}$ \\
\hline $\begin{array}{l}\text { Aut quis hos poterit flores decerpere cunctos } \\
\text { Vt stipatus eat, alacerque quiescat in aeuum? } \\
\text { (vv. 44-5) }\end{array}$ & $\begin{array}{l}\text { Florigeras sedes, iucundo et murmure riuos } \\
\text { Vndique stipatos floribus atque rosis } \\
\qquad(74,5-6)\end{array}$ \\
\hline
\end{tabular}

Le affinità sono evidenti; ma ci si potrebbe chiedere se esse siano effettivamente indizio di una relazione, o non possano semplicemente risalire al bagaglio comune della formazione carolingia, derivato in larga parte dalla poesia cristiana tardoantica. Inoltre, alcuni di questi componimenti - in particolare la Concordia Regularum e il carme 41 di Teodolfo, che costituisce l'introduzione in versi alla sua Bibbia dovevano essere considerati fin dalla loro origine 'autorevoli', e in quanto tali potevano essere soggetti a imitazioni. Attribuzioni a ambienti o scrittori in base a pure coincidenze terminologiche o sintagmatiche, se non rafforzate da altri elementi, non dimostrano molto nel caso di una letteratura cosi imitativa come è quella dei poeti in verso quantitativo dell'età carolingia. Sarà opportuno perciò analizzare un po' più da vicino questi testi paralleli, per ricavare da essi tutti gli elementi possibili.

Sul piano prosodico, Rädle osserva che nel primo dei cosiddetti Carmina Ananiensia - un componimento in esametri sul Natale conservato come si è detto nel Parigino lat. 8812 - e nei prologhi esametrici dell'Epitome Marrier e della Concordia Regularum si riscontra una percentuale pressoché identica di irregolarità rispetto alla norma classica, consistenti soprattutto nell'allungamento di vocale breve in arsi davanti a cesura, e rileva che tale fenomeno è presente in modo massiccio già nel prologo di Taione; a simili particolarità non apparirebbero estranei neanche Smaragdo e Teodolfo. Le idiosincrasie metriche e prosodiche sembrerebbero corrispondere a un livello linguistico meno appariscente rispetto a quello lessicale, ma più personale e interiorizzato, e eventuali affinità tipologiche di questo genere potrebbero costituire un indizio di maggior peso di un'identità di ambiente o autore, perché esse sono difficilmente riproducibili in un processo di pura e semplice imitazione.

Poetria Nova. A CD-Rom of Latin Mediewion Poetry (650-1250 A.D.). With a Gateway to Classical and Late Antiquity Texts, zaverdend P. Mastandrea - L. Tessarolo, Firenze 2001. 
Nel nostro caso, il prologo della Concordia Regularum di Benedetto di Aniane e quello dell'Epitome Marrier sembrano presentare sostanzialmente le medesime caratteristiche metriche e prosodiche, mentre differenze più o meno spiccate si registrano nei confronti degli altri testi e autori citati. I prologhi metrici dell'Epitome Marrier (EM) e della Concordia Regularum $(C R)$, entrambi piuttosto ampi e di estensione curiosamente analoga (60 versi $E M, 63 C R)^{53}$, appaiono molto simili anche nelle loro regole di composizione: la cesura principale prevalente è la pentemimera (44 volte in EM, 47 in $C R$ ), ma vengono usate anche l'eftemimera (15 volte in entrambi i testi) e la tritemimera (che ricorre da sola una volta in entrambi i testi, ma abbastanza spesso in associazione con le prime due); l'interruzione di parola dopo la prima sillaba del terzo piede non è considerata obbligatoria (non si trova in 7 versi di $E M$, in 3 di $C R$ ); la rima leonina non sembra ricercata, e le poche volte che ricorre si direbbe casuale. In entrambi i testi l'allungamento metrico di sillaba breve in arsi in fine di parola, spesso corrispondente a cesura, è frequente ${ }^{54}$, e si verifica indifferentemente al secondo, al terzo e al quarto piede; altri piccoli scostamenti rispetto alla prosodia classica si riscontrano in modo occasionale ${ }^{55}$. Diamo la tabella completa di queste particolarità prosodiche $^{56}$ :

53. Vien da chiedersi se il numero di versi di questi prologhi non fosse in qualche modo indotto dalla rigatura più consueta nello scriptorium dell'autore, e se essi non fossero composti ad esempio in modo da occupare esattamente due pagine consecutive. A semplice titolo di cronaca riferisco che il manoscritto di San Gallo dell'Epitome Marrier ha esattamente 31 righe per pagina, ma che i due prologhi non rispettano in esso nessun criterio perspicuo di impaginazione.

54. Cfr. Rädle, Studien zu Smaragd cit., p. 43.

55. Ambiguo è l'effetto di $h$ - iniziale di parola nel prologo dell'Epitome Marrier : in due casi (vv. 27 e 60) essa sembra fare posizione, ma lo stesso non avviene ai vv. 34, 43, 55. Nell'unico caso paragonabile della Concordia Regularum (v. 58) la $h$ - fa posizione. Al v. 55 della Concordia Regularum la $h$-iniziale impedisce la sinalefe con la vocale precedente, cosa che non avviene al v. 56 dell'Epitome Marrier.

56. Non sono state considerate irregolarità né la doppia quantità (breve e lunga) di tenebras che ricorre nel prologo della Concordia Regularum, né la lettura di sophiae con la - $i$ - lunga al v. 7 dell'Epitome Marrier, secondo l'accentazione greca e moderna (incostante nel medioevo : ricorre ad esempio sempre in Teodolfo, ma solo occasionalmente in Alcuino). Al v. 28 dell'Epitome si è preferito accogliere a testo la forma di $S$, un meno classico uenerare, in luogo di quella di R,uenerari; se si accogliesse quest'ultima, ricorrerebbe qui un'indebito accorciamente dis

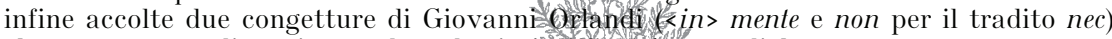
che permettono di ovviare a due ulteriondifincolta

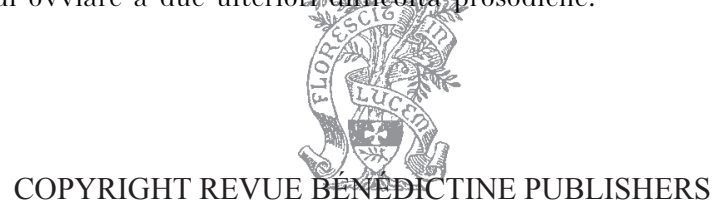




\section{Epitome Marrier :}

\begin{tabular}{|c|c|c|}
\hline 3 & Verba salutifera nostros componere mores & -a allungata in arsi al terzo piede \\
\hline 8 & Lucidior auro uitro praeclarior omni & -or allungato in arsi al secondo piede \\
\hline 9 & Mellifluo gustu cuncta redolentia uincens & -a allungata in arsi al quarto piede \\
\hline 17 & $\mathrm{Vt}$ digna fieri possent quae pauca relatu & -a allungata in arsi al secondo piede \\
\hline 27 & Aecclesia reboans laudat hunc arbiter ipse & -a allungata in arsi al secondo piede \\
\hline 32 & Floribus aspersa redolent pulcherrima uisu & -a allungata in arsi al terzo piede \\
\hline 41 & Sensus et extimuit crebra suspiria iactans & -a allungata in arsi al quarto piede \\
\hline 42 & Vocibus et magnis quasi sub pondere clamans & $\begin{array}{l}\text { quasi interpretato come spondeo anziché } \\
\text { come pirrichio }\end{array}$ \\
\hline 43 & $\begin{array}{r}\text { Quis ait hos hominum poterit percurrere } \\
\text { campus }\end{array}$ & quis con sillaba lunga \\
\hline 45 & Vt stipatus eat alacerque quiescat in aeuum & -at allungato in arsi al terzo piede \\
\hline 49 & Magniloqui studeant ista qui grandia poscunt & -a allungata in arsi al quarto piede \\
\hline 52 & Exigua retinere mea ne grandia poscens & $\begin{array}{l}\text {-a allungate in arsi al secondo e al quarto } \\
\text { piede }\end{array}$ \\
\hline 53 & Amittam modica quapropter grandia linquens & -a allungata in arsi al terzo piede \\
\hline
\end{tabular}

\section{Concordia Regularum :}

\begin{tabular}{|l|l|l|}
\hline 5 & Quas lustrare suo iussit ex lumine noctes & -it allungato in arsi al quarto piede \\
\hline 12 & Nec oculis lucem poterat intendere clausis & -at allungato in arsi al quarto piede \\
\hline 15 & Fulgidus in carne patuit sol uerus eoi & -it allungato in arsi al quarto piede \\
\hline 18 & Surgit et exinde nimium sat turba beata & -e allungata in arsi al terzo piede \\
\hline 21 & Astrigerus ordo roseo uestitus amictu & -us allungato in arsi al secondo piede \\
\hline 33 & Hic opere uerbisque suis documenta salutis & -e allungata in arsi al secondo piede \\
\hline 44 & Multigenos placuit unoque scribere libro & -it allungato in arsi al terzo piede \\
\hline 51 & Vna fides cunctos docuit et spiritus unus & -it allungato in arsi al quarto pied/e \\
\hline 55 & Sumite haec, monachi, monita quae regula & -a allungata in arsi al quarto piede \\
\hline 58 & Haec est uera uia, porgit haec pocula uitae & -a allungata in arsi al terzo piede \\
\hline 59 & Pabula dulciflua melle quae dulcius exstant & -a allungata in arsi al terzo piede \\
\hline 62 & Te, Trinitas, rogito, nobis iter esto salutis & -i- abbreviata \\
\hline
\end{tabular}

Diverso è il caso degli altri componimenti e autori citati da Rädle. In Teodolfo, che scrive per altro prevalentemente in distici, la productio della sillaba breve sembra ricorrere soltanto davanti alla cesura del pentametro ${ }^{57}$. In Smaragdo tale allungamento ricorre invece anche

57. D. Schaller, Philologische Untersiverumgen zu den Gedichten Theodulfs von Orléans, "Deutsches Archiv für Erforsctulns de pp. 38-9. 
nell'esametro, ma sempre al terzo e al quarto piede, mai al secondo; inoltre, questo scrittore sembra considerare obbligatoria la cesura pentemimera, o comunque non trascura mai di far corrispondere l'arsi del terzo piede con la fine di una parola, cosa che non fanno né il prologo della Concordia Regularum, né quello dell'Epitome Marrier. Quanto al Carmen Ananiense I, anche qui si incontrano parecchie particolarità prosodiche, ma di natura diversa: su 11 scostamenti rispetto all'uso classico segnalati da Rädle ${ }^{58}$, solo 3 volte si tratta di productio in arsi in fine di parola; 3 volte si tratta di productio in arsi, ma interno alla parola; 2 volte di productio in tesi; 3 volte di indebito accorciamento.

Dal punto di vista della tecnica versificatoria, i prologhi dell'Epitome Marrier e della Concordia Regularum appaiono dunque singolarmente simili; così come numerosi sono gli elementi lessicali comuni fra essi, rilevati sopra, più numerosi di quelli che accomunano l'Epitome Marrier agli altri testi di ambiente visigotico individuati da Rädle.

Le affinità diventano più strette quando il confronto si estende dai due prologhi in versi a quelli in prosa. Anche nel caso della Concordia Regularum, come in quello dell'Epitome Marrier, il prologo in esametri segue un'analoga composizione in $\operatorname{prosa}^{59}$; per ambedue i testi la coppia di prologhi configura un piccolo opus geminum, nel quale la sezione metrica ripete in forma poetica quanto è già stato detto in quella prosastica, senza nulla aggiungere al suo contenuto ${ }^{60}$. Insolito e

58. RäDle, Studien zu Smaragd cit., p. 44.

59. Ci sembra che l'opinione di J. Deshusses, Le sacramentaire grégorien. Ses principales formes d'après les plus anciens manuscrits, III, Fribourg 1992 (Spicilegium Friburgense 28), p. 74 (accolta sostanzialmente anche in CSLMAG, p. 215, s.v. BENA6), che i due prologhi della Concordia Regularum corrispondano a due fasi redazionali diverse dell'opera, non possa essere mantenuta; non c'è ragione di pensare che i due prologhi non esistessero fin dall'origine, dato che corrispondono a una precisa tipologia letteraria.

60. Per quanto infrequenti, i prologhi geminati non sono però eccezionali fra gli scrittori di età carolingia. I più simili per caratteristiche a quelli della Concordia Regularum e dell'Epitome Marrier sono quelli premessi da Smaragdo di Saint-Mihiel, uno scrittore che come abbiamo visto mostra grandi affinità coi testi che stiamo esaminando, ad alcune sue opere : la Collectio epistolarum et evangeliorum (PL 102, 13-552), al commentario alla Regula Benedicti (PL 102, 689-932), al Liber in partibus Donati (ed. LöfSTEdT - Holtz - Kibre cit.) e probabilmente al commentario ai Salmi (la parte in prosa in PL 129, 1021-24; quella in versi in Rädle, Studien zu Smaragd cit., p. 100); nel primo caso i versi sono esametri, negli altri tre distici. Un prologo in prosa e uno in distici - forse influenzati da Smaragdo, come farebbero pensare alcune coincidenze letterali - premette anche Angelomo di Luxeuil ai suoi commentari alla Genesi e ai Re (PL 115, 107-552). Doppi prologhi, in prose e in versi, si trovano occasionalmente in alcune opere di Rabano Mauro (Commento Giuditta, PL 109, 539-42; Institutio clericorum, PL 107, 293-6), ma in questo trase le funzione comunicativa della parte in prosa e quella in versi appare alquanto diversa.

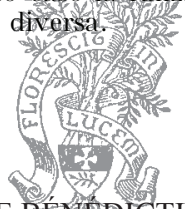


caratteristico è il fatto che né l'uno né l'altro dei due prologhi in prosa - anche stavolta di estensione abbastanza simile (circa 300 parole quello della Concordia Regularum, circa 380 quello dell'Epitome Marrier) - rappresentino formalmente una lettera di dedica: in entrambi i casi manca un destinatario specifico ${ }^{61}$, e in entrambi i casi si dichiara espressamente che l'opera non è stata eseguita su richiesta di un committente, ma per iniziativa dell'autore stesso.

Dove l'affinità appare più profonda è nella struttura logica dei due prologhi, che sembrano procedere sviluppando argomentazioni parallele :

\begin{tabular}{|c|c|c|}
\hline & Epitome Marrier (I prol.) & $\begin{array}{c}\text { Concordia Regularum } \\
\text { (I prol.) }\end{array}$ \\
\hline $\begin{array}{l}\text { Premessa in cui si spiegano le } \\
\text { circostanze che hanno portato } \\
\text { l'autore a interessarsi } \\
\text { dell'opera. }\end{array}$ & $\begin{array}{l}\text { Dum iuxta capacitatem par- } \\
\text { uitatis meae sedulo lectioni } \\
\text { sacrae operam darem, quadam } \\
\text { die manibus paruitatis meae } \\
\text { liber adhaesit ... sanctissimi } \\
\text { Iob. }\end{array}$ & $\begin{array}{l}\text { Dum communi utilitati } \\
\text { consulens ... coepi uilas re- } \\
\text { gulasque legere patrum. }\end{array}$ \\
\hline $\begin{array}{l}\text { Situazione problematica che } \\
\text { porta l'autore a rielaborare il } \\
\text { testo studiato }{ }^{62} \text {. }\end{array}$ & $\begin{array}{l}\text { At dum ego ex his primam le- } \\
\text { gendo percurrerem partem } \\
\text {... coepi deficere cybo ... sibi } \\
\text { reposuisse uolumina. }\end{array}$ & $\begin{array}{l}\text { Quas dum sagaci intentione } \\
\text { percurrerem ... ex manipulis } \\
\text { plurimis unum strenue } \\
\text { contraxisse manipulum. }\end{array}$ \\
\hline Precedenti. & $\begin{array}{l}\text { Ex quibus et ipse ante bien- } \\
\text { nium in Regnorum libro aggre- } \\
\text { gatis omnibus patrum } \\
\text { sententiis ... coniunxi libellum. }\end{array}$ & \\
\hline $\begin{array}{l}\text { Decisione di produrre un'ope- } \\
\text { ra di sussidio o di rielabora- } \\
\text { zione di quella studiata. }\end{array}$ & $\begin{array}{l}\text { Quapropter, fragilitali sen- } \\
\text { sus corporisque mei infirmitati } \\
\text { meorumque similium utilitati } \\
\text { consulens ... hunc operis } \\
\text { parui contraxi libellum. }\end{array}$ & $\begin{array}{l}\text { Quapropter, seu propter eos } \\
\text { qui eas habentes ignorant qui- } \\
\text { bus in locis fit eorum concor- } \\
\text { dia, placuit omnes ex omnibus } \\
\text { in unum coartari sententias } \\
\text { quae cum beati Benedicti } \\
\text { concordare noscuntur regula. }\end{array}$ \\
\hline $\begin{array}{l}\text { Metodo seguito nel presentare } \\
\text { il materiale. }\end{array}$ & $\begin{array}{l}\text { Eas dumtaxat diuersorum li- } \\
\text { brorum prolixo sermone expo- } \\
\text { sitas ... linquens sententias, ... } \\
\text { ne forte dum a rudibus ignora- } \\
\text { tur sensus patenter expressus } \\
\text { obscurius implicetur. }\end{array}$ & $\begin{array}{l}\text { Ita dumtaxat, ut beati Bene- } \\
\text { dicti praecederent, quibus se- } \\
\text { quenter ceterae necti possent. }\end{array}$ \\
\hline
\end{tabular}

61. La Concordia Regularum si apre con«un indirizzo del tutto generico ("Benedictus ultimus omnium abbatum abbatibus fronachis omnibus in Deo Christo salutem »).

62. Per i Moralia, l'eccessiva estedsionefrết opera gregoriana; per le Regulae, lo scarso interesse dei monaci verso quellesdiverseg falla benedettina. 


\begin{tabular}{|l|l|l|}
\hline $\begin{array}{l}\text { Dichiarazione dell'umiltà dei } \\
\text { propositi. }\end{array}$ & $\begin{array}{l}\text {.. non fastu arrogantiae } \\
\text { turgidus, nec superbiae spiritu } \\
\text { tumidus uentosis fauoribus } \\
\text { nitens incumbere, ... sed igne } \\
\text { lectionis praefatae historiae } \\
\text { flagrans. }\end{array}$ & $\begin{array}{l}\text { Nouerint tamen omnes ... quo- } \\
\text { niam non uanae laudis ins- } \\
\text { tinctu, nec arrogantiae } \\
\text { fastu, .. sed dilectionis affec- } \\
\text { tu animae meae omniumque le- } \\
\text { gere cupientium salutis } \\
\text { augmento a me esse coeptum. }\end{array}$ \\
\hline $\begin{array}{l}\text { Si chiama Dio a testimone } \\
\text { dell'umiltà dei propositi. }\end{array}$ & $\begin{array}{l}\text { Deus scit } \\
\text { mei solummodo, sed omnium } \\
\text { cordium cognitorem, quoniam } \\
\text { ipse nouit me non tumoris, } \\
\text { sed caritatis causa hoc opus } \\
\text { egisse. }\end{array}$ \\
\hline $\begin{array}{l}\text { Auspicio di incontrare il fa- } \\
\text { vore divino e richiesta di pre- } \\
\text { ghiere a Dio. }\end{array}$ & $\begin{array}{l}\text { Quem totis uiribus sedulo de- } \\
\text { precor ... quatenus ... detur re- } \\
\text { missio peccatorum. }\end{array}$ \\
\hline $\begin{array}{l}\text { Auspicio di buon accoglimen- } \\
\text { to dell'opera. }\end{array}$ & $\begin{array}{l}\text { Ergo teneant sibi illa ... dum } \\
\text { saltem mihi meisque similibus } \\
\text { concedant hunc operis exigui } \\
\text { penuriae causa coeptum medi- } \\
\text { tari libellum. }\end{array}$ & $\begin{array}{l}\text { Sumite ergo gratanter a nobis } \\
\text { utilem uobis contractum li- } \\
\text { bellum, siquidem ... lucidum } \\
\text { depinximus fauum. }\end{array}$ \\
\hline
\end{tabular}

Le affinità fra i due testi si estendono anche al livello stilistico e lessicale. Già nel confronto strutturale precedente abbiamo messo in rilievo - con carattere neretto - alcune espressioni simili o identiche; ad esse si possono aggiungere le seguenti ricorrenze:

\begin{tabular}{|l|l|}
\hline \multicolumn{1}{|c|}{ Epitome Marrier (I prol.) } & \multicolumn{1}{c|}{ Concordia Regularum (I prol.) } \\
\hline quos in codicibus sex artare decreuit & in unum coartari sententias \\
\hline ut totum sagax uellet, si posset, mandere librum & quas dum sagaci intentione percurrerem \\
\hline $\begin{array}{l}\text { quae in exponendo menti occurrerent sen- } \\
\text { tentias patrum }\end{array}$ & $\begin{array}{l}\text { occurrit animo ea quae a tepidis segnibusque } \\
\text { monachis dici assolet }\end{array}$ \\
\hline $\begin{array}{l}\text { operis parui contraxi libellum } \\
\text { operis exigui penuriae causa coeptum libellum } \\
\text { operiam in aenigmate prolata cognoscere }\end{array}$ & pro hoc exiguo opere remissionem tribuat \\
\hline etiam & quae a sancto Benedicto prolata sunt uerba \\
\hline
\end{tabular}

e parallelismi si ritrovano anche fra il prologo metrico di $E M$ e il prologo in prosa di $C R$ :

\begin{tabular}{|c|c|}
\hline Epitome Marrier (II prol.) & Goncordia Regularum (I prol.) \\
\hline $\begin{array}{l}\text { Qui meruit cunctos hominum cognoscere } \\
\text { sensum (v. 19) }\end{array}$ & $\begin{array}{l}\text { in quibusdam uero sensum eundem } \\
\text { cognoscerem }\end{array}$ \\
\hline $\begin{array}{r}\text { Multigenosque mihi perpes decerpere flores } \\
\text { (v. 37) }\end{array}$ & multigenis ex floribus nectar adsumptum \\
\hline $\begin{array}{l}\text { Hoc opus exiguum coepi non corde cothurng } \\
\text { (v. 54) }\end{array}$ & pro hoc exiguo opere remissionem tribuat \\
\hline
\end{tabular}

RB 19 
Quello che sorprende qui non è soltanto la presenza di fenomeni comuni, ma la loro serialità, e soprattutto il loro collegarsi all'interno di un'impostazione strutturale analoga ${ }^{63}$. Si può pensare che uno dei due testi sia il modello dell'altro? In tal caso si dovrebbe credere che sia il prologo della Concordia Regularum ed essere imitato dall'ignoto estensore dell'Epitome Marrier in base all'autorità di Benedetto di Aniane, mentre l'ipotesi contraria appare meno probabile. In realtà, le affinità fra i due prologhi non sembrano presentare le caratteristiche di un'imitazione: i parallelismi qui non sono esteriori, ma profondi, si direbbe quasi interiorizzati, interessano gli aspetti metrici, quelli lessicali e quelli logico-semantici, contemporaneamente e intersecandoli fra loro, laddove un'imitazione, per quanto intelligente e creativa, si limita in genere a una ripresa del modello e eventualmente a una sua rielaborazione formale ${ }^{64}$.

L'impressione è dunque che il prologo della Concordia Regularum e quello dell'Epitome Marrier siano stati scritti dallo stesso autore. Poiché l'attribuzione a Benedetto di Aniane del prologo della Concordia Regularum appare fuori discussione, si dovrà ipotizzare che a lui si debba anche il rifacimento gregoriano. In comune, oltre allo stile e alla struttura del prologo, le due opere hanno del resto un metodo di scomposizione classificatoria assai simile : come nella Concordia i testi delle regole monastiche vengono divisi in segmenti e riaccorpati poi per categorie tematiche, così nell'Epitome il testo dei Moralia viene ristrutturato secondo un preciso criterio ordinativo, che è quello del commentario esegetico all'unità minima di testo.

63. Analogie di struttura, anche se meno cogenti che per i due prologhi in prosa, si possono ravvisare anche per i due prologhi poetici. In entrambi i casi in particolare è evidenziata la funzione delle auctoritates studiate - Gregorio là, le Regulae monastiche qui - all'interno della storia della salvezza (EM, vv. 19-30; $C R$, vv. 36-43); a questa evidenziazione segue subito una metafora floreale (EM, vv. 31-38; CR, vv. 44-48); si parla poi della motivazione dell'opera (EM, vv. 39-53; CR, vv. 49-54), e si auspica un suo buon accoglimento ( $E M$, vv. 54-60; $C R$, vv. 55-62). Si può osservare anche che nella parte finale di entrambi i prologhi metrici compaiono frequenti anafore e una metafora di carattere alimentare (EM, v. 60 ; CR, v. 60).

64. Ph. Bernard, Benoît d'Aniane est-il auteur de l'avertissement Hucusque et du Supplément au sacramentaire "Hadrianum »?, "Studi medievali » 39 (1998), pp. 1120 , alle pp. 23-54, mette in guardia dal procedere ad attribuzioni di paternità in base all'identità di espressioni che potrebbero essere calchi esteriori, e che proverebbero semmai la dipendenza di un testo da un altro. Condividiamo la conclusione di Bernard che gli indizi di identità d'autore si trovano a livello più profondo ("Ce qui permet ... de démontrer l'identité d'auteur, ce sont plutôt les similitudes de vocabulaire, de tournure de pensée, de préoccupations ou de méthode de raisonnement ", p. 53). Bernard utilizza questa regola metodica per rigettares attribuzione a Benedetto di Aniane dell'aggiunta Hucusque al Sacramentariuat fregutumum; cfr. oltre, nota 77 e testo corrispondente. 
L'opera letteraria di Benedetto di Aniane e Gregorio Magno

Un'attribuzione a Benedetto di Aniane dell'Epitome Marrier, e di conseguenza di un commentario al libro dei Re di stampo marcatamente gregoriano — sia esso da identificare con quello contenuto nel Parigino lat. 15679, come è nostra convinzione, oppure no - ben si collocherebbe nel quadro di un più generale interesse che l'abate sembra avere avuto nei confronti di Gregorio. Nella Vita di Benedetto scritta da Ardo, un documento di prim'ordine perché opera di un suo discepolo diretto, si racconta che in occasione del concilio di Arles (10 maggio 813) l'abate si fermò nella città provenzale parecchi giorni, canonum secreta pandens et beati Gregorii papae homelias enucleans ignorantibus ${ }^{65}$. E questo l'unico passo di tutta la Vita in cui si fa cenno a un'attenzione di Benedetto per gli antichi scrittori ecclesiastici, e tale attenzione è rivolta proprio a Gregorio; e si noti che l'azione che egli avrebbe svolto in questa circostanza - quella di mettere i testi gregoriani alla portata di un pubblico più vasto - è la medesima prefigurata nella prefazione in prosa dell'Epitome Marrier, ed è indicata dal medesimo verbo (enucleare, per altro di uso comunissimo).

Non molto sappiamo, invero, della produzione letteraria di Benedetto di Aniane. Ad essa Ardo fa solo un breve cenno : "Fecit denique librum ex regulis diversorum patrum collectum, ita ut prior beati Benedicti regula cunctis esset, quem omni tempore ad collectam matutino legere iussit. Ex quo rursus ut ostenderet contentiosis nil frivola cassaque a beato Benedicto edita fore, set suam ex aliorum fultam esse regulam, alium collectis regularum sententiis composuit librum, cui nomen Concordia regularum dedit, ita dumtaxat ut beati Benedicti precederet sententia, ei vero racionabiliter concinentia iungerentur deinceps. Alium nichilominus ex sanctorum doctorum homeliis, quae in exhortationem monachorum sunt prolatae, coniuncxit librum eumque omni tempore in vespertinis collectis legere iussit $"{ }^{66}$. Questo passo conclude la lunghissima sezione della Vita dedicata a descrivere l'attività di Benedetto come riformatore monastico e gli adattamenti da lui compiuti nell'applicazione della

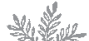

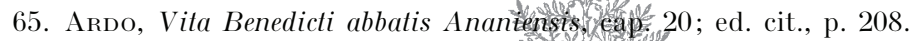

66. Ardo, Vita Benedicti abbatis Anantensis eabus 8 ; ed. cit., p. 217.

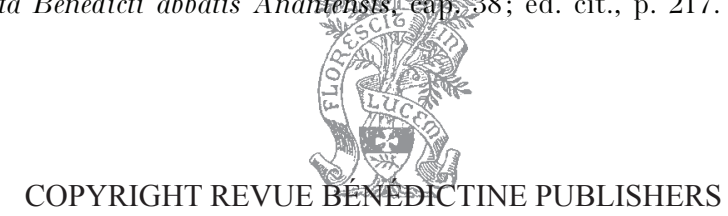


regola cassinese nei chiostri che controllava. Ardo non sta dunque fornendo un vero e proprio catalogo delle opere letterarie dell'abate, ma si limita a citare quelle che furono prodotte per la pratica monastica; il fatto che egli non parli qui di opere esegetiche scritte o compilate da Benedetto non pone difficoltà a un'attribuzione a lui di un commentario a Giobbe e di uno ai Re.

Le prime due opere citate da Ardo sono il Codex Regularum e la Concordia Regularum e non pongono particolari problemi di riconoscimento ${ }^{67}$. Più discussa è l'identificazione del liber concepito da Benedetto per la lettura serale ${ }^{68}$ e composto ex sanctorum doctorum homeliis. È stato ipotizzato che l'opera possa corrispondere al Libellus ex diversis patrum sententiis, un esemplare del quale si trovava nel monastero di Caunes, presso Carcassonne; li venne scoperto nella seconda metà del Seicento da Claude Estiennot, che ne diede notizia a Jean Mabillon, che a sua volta ne pubblicò il prologo e una breve descrizione ${ }^{69}$; dall'esemplare di Caunes, "saec. Ix aut x exaratum " a giudizio di Estiennot, questi trasse una copia, oggi conservata nel codice Parigino lat. 12770, e questa circostanza ha permesso la sopravvivenza della raccolta, dato che il manoscritto originario è in seguito andato perduto ${ }^{70}$. L'autore del Libellus è un Benedictus abbas che si qualifica come exiguus; nella prefazione, in forma di lettera a un principe di cui non viene detto il nome, egli dichiara di avere raccolto un opuscolo «in quo nulla mea resonant uerba, sed sanctorum Patrum plenus est dictis, scilicet beati Gregorii et beati Benedicti, necnon et beati Basilii, seu ceterorum priscorum Patrum »; il tema trattato è quello delle bonae e delle noxiosae cogitationes ( Narratur in eo namque origo noxiosarum cogitationum seu bonarum, argumentumque excerptum ex Patribus, qualiter prauae uitentur, et nutriantur electae»). La notizia di Mabillon prosegue

67. CSLMAG, pp. 213-6, s.v. BENA5.

68. La pratica era prescritta nella Regula Benedicti (cap. 42), dove si escludevano dalla lettura l'Eptateuco e i Re quia infirmis intellectibus non erit utile illa hora hanc scripturam audire, certo per le fantasie che potevano suscitare. Che vi fosse necessità di avere un testo collettaneo per tale pratica lo dimostra la composizione del Diadema monachorum di Smaragdo, volto al medesimo scopo (cfr. Rädle, Studien zu Smaragd von Saint-Mihiel cit., pp. 70-1).

69. Acta Sanctorum Ordinis Sancti Benedicti, IV, II a, Paris 1680, pp. 572-3; riprodotto ora in Benedicti Ananiensis Concordia Regularum cit., I, pp. 57-8, da cui cito. CSLMAG pp. 221-2 (BENA17).

70. L'esistenza di questa trascrizione è stata segnalata da P.-M. Bogaert in una recensione all'edizione Bonnerue della Condordia Regularum, nella "Revue Bénédicti-

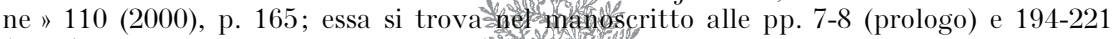
(testo). 
descrivendo in questo modo la raccolta: "Sequuntur nudae Patrum sententiae de reuelandis cogitationibus. Patres illi sunt Gregorius Magnus, sanctus Pater Benedictus, Basilius, Macarius Abbas, Paulus Aegyptius, Antonius Abbas, Vitae Patrum, Cassianus, Augustinus de periurio, et Isidorus»; e termina riportando le prime parole dell'opera: "In Christi nomine incipit libellus ex Diversis Patrum sententiss. Sententiae sancti Gregorii de lib. Moral. in Iob Pars I. Et fuit possessio eius septem millia ouium, etc. ».

Che il Benedictus abbas exiguus autore della lettera prefatoria e quindi compilatore della raccolta sia Benedetto di Aniane era già opinione di Estiennot ${ }^{71}$, e molti elementi rendono tale identificazione probabile. Per quanto la raccolta sia dedicata a un principe, il tema trattato, quello delle cogitationes, è schiettamente monastico; le auctoritates che forniscono materiale per le sententiae sono in larga parte regole monastiche, e per lo più le stesse che sono utilizzate da Benedetto per il Codex e la Concordia Regularum; il monastero di Caunes, dove si trovava il manoscritto, fu retto a lungo fra l'vin e il Ix secolo da Aniano, uno dei promotori dello sviluppo monastico nella Francia meridionale, che sappiamo in stretto rapporto con Benedetto ${ }^{72}$. Oltre che da Mabillon, la paternità di Benedetto di Aniane per la lettera prefatoria delle Sententiae è stata accolta da Raymond Étaix e da Pierre Bonnerue, che tuttavia hanno negato che la raccolta possa identificarsi con il liber di cui parla $\mathrm{Ardo}^{73}$.

In attesa che studi più approfonditi ${ }^{74}$ portino a un'esatta descrizione e valutazione delle Sententiae, ciò che importa qui è osservare che anche in questo testo, la cui attribuzione a Benedetto di Aniane appare quanto meno probabile, la presenza di Gregorio Magno, e in particolare dei Moralia, è centrale e preponderante. Nella breva lista

71. Di conseguenza Estiennot identificava il destinatario con Ludovico il Pio.

72. Si vedano le voci di J. Hourlier nel Dictionnaire d'Histoire et de géographie ecclésiastiques, XII, Paris 1953, coll. 12-17, e di R.-H. BAutier nel Lexikon des Mittelalters, II, München 1983, coll. 1580-2.

73. R. Étaix, Un florilège ascétique attribué indûment à saint Benoît d'Aniane, "Revue Bénédictine » 88 (1978), pp. 247-60, alle pp. 247-50; Benedicti Ananiensis Concordia Regularum cit., I, p. 59; CSLMAG, pp. 221-2. Fra gli elementi che hanno fatto dubitare dell'identificazione con il liber di cui parla Ardo un certo peso ha avuto il fatto che Mabillon avesse definito la raccolta come un Libellus ex diversis Patrum sententiis collectum de Confessione, mentre il tema della confessio era certo estraneo al liber; in realtà, come risulta chiaro dagli estratti di Estiennot, la qualifica de confessione appare una formula sbrigativa e erronea, e la raccolta non affronta affatto questo argomento. Le bonae et noxiosae cogitationes sono invece un tema adattissimo alle letture serali dei monaci.

74. Condotti ora da François Dolbeau, dehen ringtazio per le informazioni che mi ha fornito. 
di auctoritates che si legge nella lettera prefatoria, il grande papa ̀̀ citato al primo posto, addirittura davanti a Benedetto da Norcia; la serie delle Sententiae si apre con una trentina di estratti dai Moralia, ricavati da tutte le sezioni dell'opera; e tali estratti costituiscono da soli circa la metà dell'intera raccolta (14 pagine su 28), o almeno della raccolta come è stata trascritta da Estiennot. L'autore delle Sententiae aveva perciò letto integralmente i Moralia, e da essi aveva estrapolato tutte le pericopi che riguardavano le cogitationes: un'operazione identica, anche se ordinata a obiettivi differenti, a quelle compiute dall'excerptor dell'Epitome Marrier, che dai Moralia aveva estratto le parti strettamente indirizzate a commentare Giobbe, e dall'excerptor delle Sententiae ai Re del Parigino lat. 15679, che sempre dai Moralia aveva estratto i testimonia relativi ai Re.

Ancor più discussa, se possibile, è l'attribuzione a Benedetto di una revisione del Sacramentarium Gregorianum, caratterizzata dall'aggiunta in appendice di ulteriori materiali liturgici, distinti dal corpo principale da un raccordo redazionale noto come Hucusque ${ }^{75}$, dalla parola con cui esso inizia. La revisione fu attribuita a Benedetto da Jean Deshusses ${ }^{76}$, che rilevò fra l'altro alcuni paralleli di stile e contenuto fra il raccordo Hucusque e il prologo in prosa della Concordia Regularum: in particolare l'insistenza sul concetto di communis utilitas come movente dell'opera; l'identica definizione del carattere collectaneo (ex multis collegimus) di ambedue i lavori; la parallela esortazione ai destinatari ad accogliere gratanter l'opera; e inoltre un piccolo gruppo di analogie e identità lessicali, la più significativa delle quali è il sintagma fastu arrogantiae. In seguito la tesi di Deshusses è stata oggetto di ampio dibattito, fino al più recente intervento di Philippe Bernard, che l’ha recisamente contestata ${ }^{77}$. Secondo Bernard l'aggiunta al sacramentario e il raccordo Hucusque sarebbero stati prodotti nell'ambiente di corte in epoca compatibile con la presenza di Alcuino, e dunque parecchi

75. Pubblicato da J. Deshusses, Le sacramentaire grégorien. Ses principales formes d'après les plus anciens manuscrits, I, Fribourg $1992^{3}$ (Spicilegium Friburgense 16), pp. $351-3$.

76. Deshusses, Le sacramentaire grégorien, III cit., pp. 66-75. Nel volume Deshusses riprende il suo precedente articolo Le 'supplément' du sacramentaire grégorien. Alcuin ou saint Benoît d'Aniane?, "Archiv für Liturgiewissenschaft " 9/1 (1965), pp. 48-71.

77. Ph. Bernard, Benoît d'Aniane est-il auteur de l'avertissement Hucusque et du Supplément au sacramentaire "Hadrianum»? cit. Prima dellintervento di Bernard, CSLMAG (pp. 227-30), dopo aver riassunto il dibattito sulla questione, riteneva nel complesso l'attribuzione a Benedetto "la plus valable»; Bonnerue (Benedicti AnaNiensis Concordia Regularum cit., p. 62) olde scrive nel 1999 evidentemente senza an-

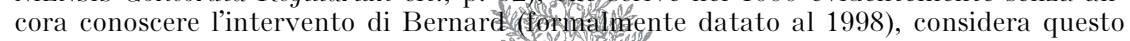
testo "désormais attribué à Benoît " sँ 
anni prima della frequentazione regia e imperiale da parte di Benedetto; i paralleli di stile si spiegherebbero con l'influenza del (preesistente) raccordo Hucusque sulla prefazione in prosa della Concordia Regularum, e non con un'identità d'autore. Non è questa la sede per entrare nel merito della questione, né chi scrive ha le competenze di storia della liturgia necessarie per poterlo fare; ci si limiterà qui a indagare se le analogie stilistiche fra l'Hucusque e il prologo della Concordia Regularum trovino riscontri anche nel prologo in prosa dell'Epitome Marrier.

Si potrebbe osservare anzitutto che alcuni parallelismi individuati da Deshusses valgono anche nei confronti dell'Epitome Marrier : anche nel prologo di quest'ultima si insiste sull'utilitas come movente dell'azione, e anche qui figura la condanna del fastus arrogantiae, e si utilizza questa precisa espressione. Più significativo è forse notare che anche nel raccordo Hucusque, come nei prologhi dell'Epitome Marrier e della Concordia Regularum, l'autore sembra seguire una traccia strutturale precisa, nella quale hanno parte importante l'esposizione del metodo usato per l'excerptio e una conclusione in cui si parla di livelli diversi di pubblico cui destinare l'opera. Esiste però anche un'ulteriore e più clamorosa affinità lessicale fra il raccordo Hucusque e il prologo dell'Epitome Marrier, che riguarda un'espressione tecnica impiegata in ambedue i casi per indicare l'adozione di un artificio redazionale al fine di ottenere chiarezza di risultati :

\begin{tabular}{|l|l|}
\hline \multicolumn{1}{|c|}{ Epitome Marrier (I prol.) } & \multicolumn{1}{|c|}{$\begin{array}{c}\text { Sacramentarium Gregorianum, } \\
\text { pref. Hucusque }\end{array}$} \\
\hline $\begin{array}{l}\text { Libuit etiam primas historiae litteras discre- } \\
\text { tionis causa minio scribere, ut dum historia } \\
\text { agnoscitur, expositio historiae utilius carpatur, } \\
\text { ne forte dum a rudibus ignoratur sensus patenter } \\
\text { expressus obscurius implicetur. }\end{array}$ & $\begin{array}{l}\text { Hanc uero discretionis gratia praefaciuncu- } \\
\text { lam in medio conlocauimus, ut alterius finis } \\
\text { alterius quoque exordium esset libelli, ita } \\
\text { uidelicet ut hinc inde ordinabiliter eisdem positis } \\
\text { libellis nouerit quisque quae a beato Gregorio, } \\
\text { quaeue sint ab aliis edita patribus. }\end{array}$ \\
\hline
\end{tabular}

L'espressione discretionis causa / gratia è comune nell'ambito della trattatistica grammaticale, e si riferisce in genere all'opposizione grafematica o fonologica fra due parole ${ }^{78}$; ma solo qui, a mia conoscenza, essa è usata per indicare degli artifici redazionali. I due artifici impiegati sono poi ovviamente diversi, dato che diversi sono

78. Essa è usata ad esempio nel De orthographia di Cassiodoro (H. Keil, Grammatici Latini, VII, Leipzig $1880,171,2 ; 173,11$ 181 $2 ; 186,1 ; 191,4 ; 207,2)$ e nell'omoni-

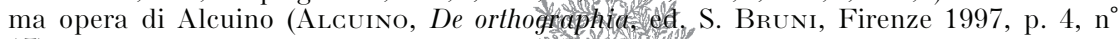
17). 
gli scopi e diverse sono le opere cui si applicano; ma l'identità dell'espressione usata parrebbe la conferma di una affinità 'profonda' fra i due testi.

Fra il prologo in prosa dell'Epitome Marrier e il raccordo redazionale Hucusque sembrano dunque esistere somiglianze di segno non diverso da quelle che esistono fra il prologo in prosa della Concordia Regularum e il raccordo Hucusque. Se l'attribuzione proposta da Deshusses dovesse essere definitivamente scartata, e andasse perciò escluso che a uno stesso autore tutti e tre i testi vadano ascritti, se ne dovrà concludere che il raccordo Hucusque abbia esercitato un’influenza precisa non solo sull'autore della Concordia, ma anche su quello dell'Epitome. Se invece l'attribuzione del raccordo Hucusque a Benedetto avrà in futuro ancora credito, si potrà notare che l'autore dell'addizione - così come quelli dell'Epitome Marrier e del Libellus sententiarum di Caunes - mostra notevole interesse verso Gregorio: per il recupero e la valorizzazione di un testo liturgico attribuito al grande papa, ma anche per il rispetto 'filologico' con cui le parti aggiunte sono state tenute distinte da quelle gregoriane.

Con i possibili indizi dell'interesse di Benedetto verso Gregorio Magno che abbiamo fin qui rintracciato sembrano invece contrastare gli opuscoli teologici attribuiti all'abate visigoto. Si tratta dei cosiddetti Munimenta fidei, che si leggono in una miscellanea conservata nel codice Parigino lat. 2390, dell'XI sec. Una gran parte dei testi che costituiscono questa raccolta, per lo più non attestati altrove, a giudizio di Jean Leclercq sarebbero da ascrivere a Benedetto, e forse ancora da lui sarebbero stati uniti ad altre trattazioni teologiche, soprattutto alcuiniane, a costituire una miscellanea incentrata sul tema della fede ${ }^{79}$. Di Benedetto in particolare sarebbero un'ampia Forma fidei, che si conclude con una Recapitulatio, una Confessio fidei, un trattato De modis amicitiarum et vera amicitia, due trattati antiadozionisti (Testimoniorum nubecula, Disputatio adversus Felicianam impietatem), una Laus hymnidica beatae Mariae in ottonari, e una lettera a un altrimenti ignoto discepolo di nome Guarnario, che discute questioni trinitarie ${ }^{80}$. Anche i trattati che compongono i Munimenta sono almeno in parte opere compilative; ma il metodo usato per la composizione appare

79. J. Leclerce, Les Munimenta fidei de saint Benoût d'Aniane, in Analecta monastica, I, Città del Vaticano 1948 (Studia Anselmiana, 20), pp. 27-74.

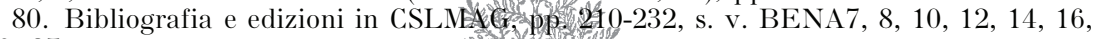
20,27 
sostanzialmente diverso da quello seguito per le compilazioni di cui abbiamo fin qui parlato — dall'Epitome Marrier, alla Concordia Regularum, alle Sententiae di Caunes - perché molto più ampio è lo spazio concesso alla rielaborazione e all'aggiunta personale del compilatore. All'interno di questi trattati l'auctoritas più usata è Agostino, certo più adatto di Gregorio a sostenere argomentazioni teologiche; ma l'assenza pressoché totale di citazioni gregoriane, in uno scrittore come Benedetto di Aniane che per altri aspetti sembrerebbe assai filogregoriano, può apparire sorprendente ${ }^{81}$. A questa discrepanza nell'impiego delle auctoritates corrispondono del resto anche notevoli differenze di ordine stilistico rispetto alle opere sicuramente ascrivibili a Benedetto: la prosa dei Munimenta appare assai polemica e fiorita, del tutto diversa da quella asciutta e didattica del prologo della Concordia Regularum, cui potremmo aggiungere eventualmente quelli dell'Epitome Marrier, della raccolta di Caunes e, forse, del raccordo Hucusque. Le differenze di stile e di tono appaiono tali che si fatica a giustificarle semplicemente con l'adesione a generi letterari diversi; più semplice sarebbe ipotizzare qui una differenza di autore.

A ben vedere, però, l'attribuzione dei Munimenta fidei e della raccolta del Parigino lat. 2390 a Benedetto d'Aniane non appare ancora definitivamente dimostrata ${ }^{82}$. Tale attribuzione, che si deve a Étienne Baluze ed è stata in seguito accolta senza particolari verifiche, si basa sostanzialmente su due fatti : 1) alcuni dei testi compresi nella raccolta sono una confutazione delle tesi adozionistiche, e Benedetto fu attivamente coinvolto nella repressione di tale dottrina; 2) il nome dichiarato dell'autore di una parte dei testi che compongono la raccolta (la Confessio e la Disputatio adversus Felicianam impietatem) è Benedictus levita, evidentemente il medesimo Benedictus che figura senza altra specificazione come estensore dei due scritti diretti a Guarnario, l'Epistola e la Testimoniorum nubecula. Nessuna di queste due ragioni appare tuttavia conclusiva. L’attività antiadozionistica di

81. Sulle fonti dei Munimenta cfr. Leclerce, Les Munimenta fidei de saint Benoît d'Aniane cit., pp. 70-1. All'interno della raccolta si incontra in realtà anche una Fides sancti Gregorii papae urbis Romae, per altro affiancata ad altre professioni di fede, ma si tratta di un errore : il testo è tratto infatti da Gregorio di Nazianzo (Ibidem, p. 23). Si fatica a credere che un simile errore possa essere attribuito a uno esperto delle opere gregoriane quale doveva essere Benedetto.

82. Pierre Bonnerue (Benedicti Ananiensis Concordia Regularum cit., I, p. 61) segnala con un certo imbarazzo l'assenza devily himenta dalla lista delle opere di Benedetto presentata da Ardo, ma non sembraduletare della loro attribuzione tradizionale. 
Benedetto di Aniane è chiaramente attestata come impegno pastorale ed ecclesiastico; ma in nessun luogo si trova menzione di interventi teologici da lui prodotti, analoghi a quelli preparati da Alcuino o da Paolino di Aquileia. Quanto al nome, già Mabillon provava qualche imbarazzo di fronte al titolo di levita che l'autore si attribuisce; lo studioso riteneva di poter identificare il personaggio con Benedetto di Aniane soltanto a costo di considerare le opere nelle quali compare questo titolo come suoi scritti giovanili, precedenti all'elevazione al sacerdozio e all'abbaziato, e lasciava in definitiva un margine di dubbio $^{83}$. Ben poco sappiamo in realtà delle ordinazioni ecclesiastiche di Benedetto e della loro cronologia ${ }^{84}$; si può osservare comunque che l'impegno teologico profuso e il tono autorevole dei Munimenta sembrano più adatti a un maestro di esperienza che a un giovane studioso, e che, dall'altro lato, la Disputatio adversus Felicianam impietatem non può essere precedente al sinodo di Ratisbona del 792, che condannò per la prima volta Felice di Urgell, e al contrario il fatto che si parli dell'eresia adozionista come nuperrime rediviva ${ }^{85}$ può far spostare i termini in epoca anche di molto più recente ${ }^{86}$. Del resto quanto l'autore dei Munimenta ci fa capire di sé stesso non trova riscontri precisi in ciò che conosciamo della biografia di Benedetto; e gli sforzi di Leclercq di trovare coincidenze e allusioni sembrano soprattutto conseguenze dell'identificazione aprioristica dei due personaggi ${ }^{87}$.

83. "Itaque praedicta opuscula, quae quidem Benedicti Anianensis esse videntur, ab eo nondum presbytero, sed levita scripta sunt, si non fallit codicis inscriptio in titulo levitae. Certe Benedictum illum, quisquis tandem sit, abbatem exstitisse inde colligitur quod Guarnarium filium suum nominat »(PL 103, 394 B).

84. Una notizia biografica su Benedetto si trova in PH. Depreux, Prosopographie de l'entourage de Louis le Pieux ('781-840), Sigmaringen 1997, pp. 123-129, n 43, dove tuttavia non si parla che molto marginalmente della sua attività letteraria.

85. PL 103, 1381D.

86. La controversia adozionista si trascinò a lungo anche dopo il concilio di Francoforte del 794 e i pronunciamenti che ne seguirono, e non è chiaro quando essa possa considerarsi definitivamente superata. Il fatto che Agobardo di Lione, in una data successiva alla morte di Felice di Urgell (818 circa) abbia avvertito l'esigenza di scrivere l'Adversus dogma Felicis (Agobardi Lugdunensis Opera omnia, ed. L. Van Acker, Turnhout 1981 [CCCM 52], pp. 73-111; E. Boshof, Erzbischof Agobard von Lyon. Leben und Werk, Köln-Wien 1969, pp. 78-80) fa pensare che l'argomento fosse considerato in quel momento ancora attuale. L'espressione Feliciana haeresis con cui nei Munimenta è designato l'adozionismo, non frequentissima, si trova però ad esempio nel commentario a Matteo di Pascasio Radberto (PL 120, 351B.688A.826B.848B. 853C), scritto a più riprese fra l'820 e l'860\%

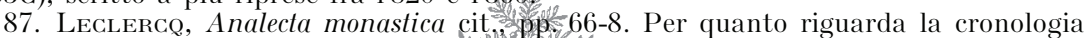
— se non dei singoli testi, almeno dêla paecola in generale — si può ancora notare che i testi alcuiniani compresi nella racoolla ted 1 arigino lat. 2390 (la lettera a Eulalia

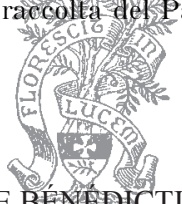


Al di là dei singoli testi accolti nel Parigino lat. 2390, per i quali sarebbe necessario riprendere uno studio specifico, difficilmente sarà comunque attribuibile a Benedetto di Aniane la raccolta come oggi è organizzata. Nell'Epistola ad Guarnarium, ultimo testo della serie e uno di quelli il cui autore è esplicitamente chiamato Benedictus, viene contestata, giudicandola pericolosa, una terminologia cristologica fondata su una particolare traduzione in latino della parola hypostasis :

Neve aliquo fatigeris a superstitioso argumento inscio de fide apochripho, scito professu Greco fidem esse hoc modo, una usia, ac si dicat, una natura vel essentia, tres ipostases, quod resonat in Latinum vel tres personas vel tres substancias. Nam Latinitas proprie non dicit de Deo nisi essentiam. Substantiam vero non proprie, sed pronunciat abusive: quoniam vera substantia apud Grecos persona intelligitur, non natura. Unde apud modernos scolasticos, maxime apud Scotos, iste sillogismus delusionis, ut dicant trinitatem, sicut personarum, ita esse substantiarum, quatinus si adsenserit illectus auditor trinitatem trium esse substantiarum Deum, trium derogetur cultor deorum; si autem abnuerit, personarum denegator culpetur; culpetur propter idioma Grecum, derogetur propter sermonem Latinum ${ }^{88}$.

L'accenno ai moderni scholastici, e in particolare agli Scoti, non sembrerebbe potersi riferire ad altri che a Giovanni Scoto Eriugena e alla sua cerchia, che effettivamente si occuparono del problema qui trattato in termini molto simili a quelli contestati nell'Epistola ad Guarnarium. Un passo del Periphyseon di Giovanni, in particolare, recita $^{89}$ :

Deus est trinitas et unitas, hoc est tres substantiae in una essentia et una essentia in tribus substantiis vel personis. Sicut enim graeci $M I A N$

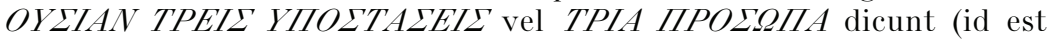
unam essentiam tres substantias vel tres personas), ita romani unam essentiam tres substantias vel tres personas. In hoc tamen videntur differre quod graecos MONEN YIIO $T A E I N$ (id est unam substantiam) dicere non repperimus, latini vero unam substantiam tres personas fraequentissime solent dicere.

De animae ratione, il De Trinitate, le XXVIII quaestiones de Trinitate, la lettera 205 agli abati e ai monaci della Gothia) sono tutti posteriori al 799.

88. MGH, Epistolae IV (Karolini aevi II), ed. E. DümmLer, Berlin 1895, pp. 561-3. Nell'edizione la lettera è regolarmente attribuita a Benedetto di Aniane. Le affermazioni qui contenute riecheggiano, in modo un po' confuso, Agostino, De Trinitate, V, viii-ix, 10 (S. Aureli Augustini De Trinitatelibri XV, ed. F. Glorie, I, Turnhout 1968 [CCSL 50], pp. 216-7).

89. Iohannes Scotus Eriugena, Periphyeseon 14 , 567BC, ed. É. Jeauneau, Turnhout 1997 (CCCM 162), pp. 56-57. 
Il Periphyseon fu scritto da Giovanni Scoto non prima dell'862. Se il passo dell'Epistola si riferisce a quest'opera, ciò impedisce evidentemente di attribuirne la paternità a Benedetto di Aniane, morto in quel momento da oltre quarant'anni; e anche se si parlasse qui più genericamente di un insegnamento di Giovanni o di altri Scoti precedente alla sua codificazione ufficiale in un'opera filosofica, non sarebbe comunque possibile risalire molto più indietro nel tempo. Possono esistere, ben inteso, spiegazioni diverse di questa apparente incompatibilità con l'attribuzione tradizionale della lettera — si potrebbe pensare che la frase sugli Scoti sia stata interpolata in seguito $^{90}$-; ma sarà comunque opportuno, fino a quando la questione della paternità dei Munimenta e delle sue varie parti non sarà stata riesaminata a fondo, astenersi dal considerare l'opera una fonte sicura per la conoscenza del pensiero e dello stile di Benedetto, e dal trarre sulla base di essa conclusioni che potrebbero rivelarsi alla fine fuorvianti ${ }^{91}$.

Un'attribuzione dell'Epitome Marrier a Benedetto di Aniane appare plausibile per una serie di elementi interni e esterni all'opera. La provenienza da un ambiente di cultura visigotica, già rilevata da Rädle, appare confermata e trova ulteriore conforto nella circolazione del testo nella Francia meridionale (manoscritto di San Gallo) e centrale (manoscritto di Oxford). Forse anche l'onorifica menzione di Paterio che figura nel prologo potrebbe rappresentare un elemento a favore di tale ambientazione, perché le opere di questo scrittore erano note in terra visigotica ${ }^{92}$ e per la via visigotica potrebbero essersi

90. Ipotesi non cosi peregrina, visto che questa lettera presenta una doppia conclusione, la prima delle quali (al f. $110 \mathrm{v}$ del manoscritto, dove si legge un evidente «Valeto " rubricato) precedente alla sezione che abbiamo citato; si potrebbe perciò pensare che a una lettera originaria più antica sia stato aggiunto, all'epoca della polemica con gli Scoti, un paragrafo finale.

91. A Benedetto sono attribuite altre due lettere, una a Giorgio, suo successore come abate di Aniane, e una a Nebridio, arcivescovo di Narbona, entrambe conservate all'interno della Vita di Ardo. Il loro valore per un'eventuale comparazione stilistica è però nullo, in quanto esse vennero scritte in punto di morte, dopo l'improvvisa malattia che aveva colpito l'abate il 7 febbraio 821: possono certo corrispondere alla sua volontà, ma non furono scritte, e probabilmente neppure dettate, da lui in persona.

92. Wilmart, Le recueil grégorien de Paterius cit. Il Liber testimoniorum di Paterio fu utilizzato ampiamente anche da Taione Nis Saragozza; cfr. P. Meyvaert, The Enigma of Gregory the Great's Dialogues : Depespolse to Francis Clark, "The Journal of

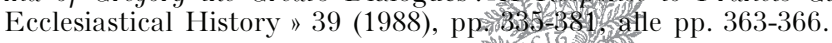

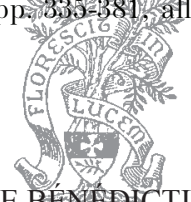


diffuse in Gallia in epoca carolingia ${ }^{93}$. All'interno di questo ambiente, elementi di carattere stilistico - la tecnica versificatoria e la prosodia; la struttura dei prologhi; la comunanza di espressioni e sintagmi - e di carattere culturale — l'importanza assegnata a Gregorio Magno fanno propendere per un'identificazione dell'autore con Benedetto di Aniane.

Ulteriori argomenti a vantaggio di tale identificazione porta il riconoscimento - che pare a noi quanto meno probabile - del commentario ai Re del Parigino lat. 15679 con quello di cui parla il prologo dell'Epitome Marrier. I rapporti fra Teodolfo di Orléans, organizzatore della raccolta esegetica che si ritrova in questo manoscritto, e Benedetto erano stretti. L'abate di Aniane mandò a Teodolfo, visigoto come lui, un gruppo di monaci per riformare il monastero di Micy, come si è già detto ${ }^{94}$, e in questa occasione Teodolfo ringraziò Benedetto con un componimento in distici (carm. $30)^{95}$; un confronto fra il prologo dell'Epitome e i carmi di Teodolfo rivela del resto varie affinità stilistiche, dovute a influenze reciproche o a un utilizzo molto prossimo di modelli comuni. Non ci sarebbe nulla di strano a immaginare che i monaci di Aniane abbiano portato a Orléans anche un commentario biblico preparato dal loro abate, e che Teodolfo, che ne conosceva e apprezzava l'autore, l'abbia inserito nella sua miscellanea, probabilmente copiata proprio a Micy, dove in seguito il manoscritto fu conservato. La circostanza che due dei padri utilizzati per la compilazione - Eucherio e Cesario - siano originari della Francia centro-meridionale, poco significativa se isolata, si attaglia però perfettamente all'ipotesi di un'elaborazione del testo in quella regione.

93. Un indizio in proposito potrebbe essere il suo utilizzo - tacito, ma massiccio da parte di Claudio di Torino (cfr. Italiani, La tradizione esegetica nel commento ai Re di Claudio di Torino cit.). Meno significativa sembrerebbe la presenza del Liber testimoniorum nel monastero Teodolfino di Fleury, perché il manoscritto dell'opera che da qui proviene (ms. PARIGi, Bibliothèque nationale, n.a.l. 1597, fine VIII sec.; CLA V, 687) sarebbe precedente a Teodolfo. È vero però che non tutti i problemi che riguardano questo importante codice, intorno al quale Löwe costrui la teoria della scuola scrittoria carolingia di Fleury (CLA VI, p. [xix]), possono dirsi definitivamente risolti : manca ad esempio la prova che esso sia davvero stato scritto a Fleury, perché se anche il personaggio di nome Dodo che risulta il committente del manoscritto potesse essere davvero identificato con un abate Ido che risulta avere retto il monasterio negli anni fra il 772 e il 780 (come proposto da Wilmart, Le recueil grégorien de Paterius cit., p. 88; cfr. anche M. Mostert, The Library of Fleury. A provisional list of manuscript, Hilversum 1989, p. 240), nulla impedises di pensare che il codice sia stato copiato altrove.

94. Cfr. sopra, nota 24.

95. MGH, Poetae, I, cit., pp. 520-2. 
Contro l'ipotesi di attribuzione restano alcuni argomenti ex silentio, che in quanto tali non ci sembrano avere gran peso. Il primo è la mancata citazione di un commento a Giobbe e di un commento ai Re nel presunto catalogo delle opere di Benedetto presentato da Ardo; si è già detto però che la lista di Ardo non è un vero e proprio elenco di opere, ma la semplice menzione dei sussidi specificamente approntati da Benedetto per la pratica monastica, all'interno dei quali un'opera di carattere strettamente esegetico poteva non essere significativa.

Il secondo è il mancato accoglimento dell'Epitome Marrier nella miscellanea esegetica del Parigino lat. 15679, dove figura invece il commentario ai Re che a nostro parere potrebbe essere quello con essa collegato. Nella raccolta di Teodolfo esiste in effetti un commento al libro di Giobbe, ma esso è costituito da un'ulteriore e più sintetica epitome dei Moralia (pp. 227-293), dal titolo Expositio in Iob a sancto Gregorio, finora non studiata ma che non sembra avere nulla a che fare con l'Epitome Marrier. Supponendo che l'Epitome Marrier e il commentario ai Re siano entrambe opere di Benedetto, ci si potrebbe domandare perché Teodolfo abbia fatto ricorso a un'opera del suo illustre collega soltanto nel secondo caso, e abbia invece preferito un testo diverso per commentare il libro di Giobbe. La domanda è, come si vede, del tutto teorica: è sufficiente notare che, ammesso che Teodolfo fosse in possesso dell'Epitome Marrier, cosa tutt'altro che sicura, non aveva certo obbligo di usarla, soprattutto se poteva far predisporre un altro commento che riteneva più adatto alla bisogna, o già l'aveva a disposizione ${ }^{96}$.

Può sorprendere infine il fatto che di eventuali commentari a Giobbe e ai Re preparati da Benedetto di Aniane non parlino altri scrittori

96. Il commentario ai Re venne scritto, per esplicita ammissione dell'autore, due anni prima dell'Epitome Marrier; si potrebbe perciò anche ipotizzare che la miscellanea esegetica di Teodolfo sia stata elaborata in questo lasso di tempo, e che il suo autore avesse a disposizione la prima opera, ma non ancora la seconda. Al di là di questa considerazione, che rimane ovviamente una mera possibilità, si può comunque osservare che mentre per il libro di Giobbe Teodolfo aveva a disposizione un commento continuo, anche se troppo ampio e di natura particolare, come i Moralia, che poteva far epitomare con uno sforzo non eccessivo - e comunque non di molto superiore a quello di una eventuale copiatura continua dell'Epitome Marrier - , per i libri dei Re un simile commento continuo non esisteva. In questa situazione l'impiego di preesistenti commentari per quaestiones e sententiae era dunque una necessità, mentre per Giobbe si poteva senza difficoltà ricorrere alla più autorevole fonte remota. Si osservi ancora che nell'ambiente di Micy era probabilmente disponibile anche un altro commentario a Giobbe, quello di Filippo (cfr. M. Gorman, The Manuscripts and Printed Editions of the Commentary on Job by Phitppus, "Revue Bénédictine "116, 2006, pp. 193-232, alle pp. 204-5); Teodolfodove ex arere dunque a disposizione quindi una

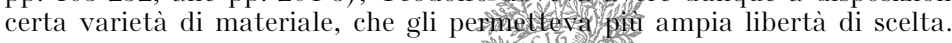

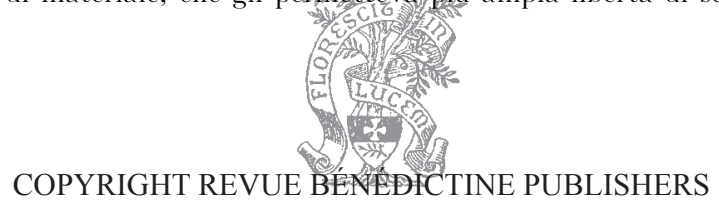


carolingi. Si può osservare, in ogni caso, che di una delle tre opere di Benedetto citate da Ardo, il Liber ex sanctorum doctorum homeliis, non rimane oggi più alcun esemplare, e che dunque la fama di Benedetto non sembra aver necessariamente costituito una buona garanzia per la sopravvivenza e la diffusione dei suoi scritti. Più singolare sembrerebbe il fatto che di un eventuale commentario ai Re di Benedetto non parlino nemmeno Claudio di Torino, il primo grande esegeta carolingio di questa parte della Bibbia, anch'egli visigoto, né il committente e dedicatario del commentario ai Re di Claudio, Teodemiro, abate di Psalmody, uno dei più ricchi e importanti monasteri della Settimania, distante da Aniane non più di 50 miglia ${ }^{97}$. In realtà Claudio e Teodemiro non citano e forse non conoscono alcun commentario visigotico sui Re; eppure un'opera siffatta - sia essa da identificare o no con quella contenuta nel Parigino lat. 15679 - dovette esistere, perché di essa parla a chiare lettere il prologo dell'Epitome Marrier, delle cui ascendenze visigotiche non par più lecito dubitare. Il silenzio di Claudio e Teodemiro non pregiudica dunque l'esistenza del commentario visigotico, e lascia immutata la questione di chi ne sia stato l'autore.

Ai margini dei problemi attribuzionali, un interesse preciso di Benedetto di Aniane nei confronti di Gregorio Magno sembra emergere dalla documentazione: una documentazione non sempre del tutto sicura, ma che pare nel complesso convergere a indicare che il grande pontefice fu considerato dall'abate come la principale delle sue auctoritates. La profondità di questo legame potrebbe fornire una chiave per interpretare anche l'interesse di Benedetto di Aniane verso la regola di Benedetto da Norcia, pregno di enormi conseguenze per la promozione che di essa l'abate svolse nell'impero carolingio. Il monachesimo benedettino ananiese potrebbe avere cioè alle sue origini una forte, e finora insospettata, impronta gregoriana.

Milano,

Paolo Chiesa

\section{Università degli Studi}

\section{0,0}

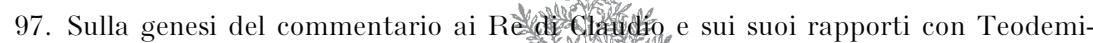
ro cfr. Gorman, The Commentary on Kingisof ef doughus of Turin cit., pp. 116-9. 


\section{APPENDIGE}

\section{Due prologhi dell'EPITOME MARrier}

Sono qui pubblicati i due prologhi dell'Epitome Marrier, sulla base di entrambi i testimoni manoscritti che ce li riportano ( $S$ : Sankt Gallen, Stiftsbibliothek, 205; $R$ : Città del Vaticano, Biblioteca Apostolica Vaticana, Reg. lat. 306). Alcuni errori condivisi (l'insostenibile quoniam alla n. 8, che è stato modificato in quodammodo grazie a un suggerimento di Rossana Guglielmetti; nimbibus, n. 10; sensui, n. 17; coturno, v. 49; superius, v. 50) mostrano la discendenza dei due manoscritti da un comune archetipo; il codice $R$, di epoca più recente, non sembra derivare da $S$, come indicano alcune lezioni del primo superiori a quelle del secondo ${ }^{1}$ e soprattutto il fatto che in $R$ la parte iniziale dell'opera è riprodotta nella sua disposizione originaria, senza cioè l'accessus a Giobbe che spezza in $S$ la continuità dei due prologhi con il successivo testo. In sede di ricostruzione testuale i due manoscritti sono stati perciò considerati di pari valore. A dispetto della sua maggiore antichità, il codice $S$ appare viziato da un numero di errori di copia analogo a quello di $R$; per gli aspetti ortografici abbiamo comunque seguito il primo, con qualche tacita normalizzazione che appariva necessaria.

Nel prologo in versi sono state accolte due piccole correzioni congetturali (vv. 22 e 51), delle quale ringrazio Giovanni Orlandi, che permettono con minimo sforzo di ovviare a più gravi anomalie prosodiche. Dubbi rimangono almeno sulla lezione uenerare / uenerari al v. 28 , dove la correttezza prosodica classica di $R$ appare in contrasto con quella morfologica di $S$; e sul genere del sostantivo flos, che abbiamo considerato con $R$ maschile secondo l'uso classico (multigenos ... hos ... flores ... cunctos : vv. 37, 44), ritenendo un localismo deteriore le forme di $S$ (multigenas ... has ... flores ... cunctas). In apparato sono registrate le varianti non accolte dei due manoscritti, ad eccezione di quelle grafiche, e le congetture degli studiosi; quando non viene indicata, la lezione pubblicata dal Marrier è uguale a quella di $R$ o è palesemente inferiore ad essa.

1. In gran parte tuttavia ricostruibili in vvia congetturale da parte di un correttore medievale. Si osservi che al v. 41 la lezione a 4 ternativa extabuit di $R$, migliore di extimuit quanto al senso, ma non accettablley per ó gioni metriche, mostra che il testo è stato fatto oggetto di qualche attenzione efitioge

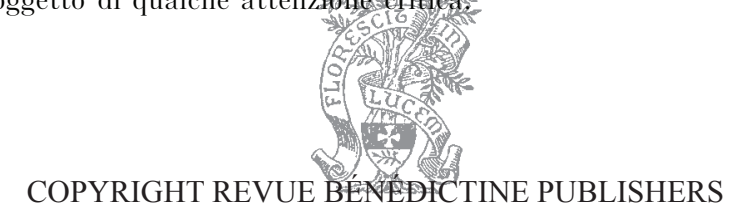




\section{In Christi nomine ${ }^{2}$ \\ INCIPIT PRAEFATIO IN EXPOSITIONEM LIBRI IOB ${ }^{3}$}

Dum ${ }^{4}$ iuxta capacitatem paruitatis meae sedulo lectioni sacrae operam darem, quadam die manibus paruitatis meae liber adhaesit $\mathrm{a}^{5}$ beato Gregorio editus in historiam ${ }^{6}$ sanctissimi Iob. Is $^{7}$ etenim doctor egregius diuino adflatus spiramine atque de fonte potatus superno, ceu rutilans flumen in praefati uiri historiam diffundens, tanto eam facundo protelauit eloquio ut ex ea uelut clarificos soles $\mathrm{xxx}$ et $\mathrm{v}$ ederet libros, quos in codicibus sex artare decreuit.

At dum ego ex his primam legendo percurrerem partem, nimio accensus amore pellectusque ita est animus dulcedine quadam, ut totum sagax uellet, si posset, mandere librum; sed quodammodo ${ }^{8}$ prae ubertate eloquentiae praefati uiri, uelud paruulus lacte suetus, illo quo fortes aluntur coepi deficere cybo. Is ${ }^{9}$ etenim mirabilis doctor, diuinis imbribus ${ }^{10}$ haustis ${ }^{11}$, studuit luculento enodare affatu eas quae $^{12}$ in exponendo menti occurrerent ${ }^{13}$ sententias patrum; ex quibus protensis numerosa in praefatam historiam contraxit ${ }^{14}$ uolumina, quas nempe norunt, quibus sacra non latet Scriptura, a sancto uiro Paterio nomine mirabili opere abstractas propriisque uoluminibus redditas, lucida sibi reposuisse uolumina. Ex quibus et ipse ante biennium in Regnorum libro aggregatis omnibus patrum sententiis, maxime autem sanctissimi papae ${ }^{15}$ Gregorii, unum quem non puto temnendum coniunxi libellum.

Quapropter fragilitati ${ }^{16}$ sensus $^{17}$ corporisque mei infirmitati meorumque ${ }^{18}$ similium utilitati consulens, erexi me contra memet, non fastu arrogantiae turgidus nec superbiae spiritu tumidus uentosis fauoribus nitens incumbere, Deus scit, sed igne lectionis praefatae historiae flagrans, quam toto nisu memoriter ut intellectam retinere ualeam laborans, hunc operis parui contraxi libellum. In quo opere nempe nullum meo, ut reor, sensu fuscatum sermonem permiscui, sed eiusdem uenerabilis uiri dicta perlustrans, eas dumtaxat diuersorum librorum prolixo sermone expositas, quas supra taxaui, linquens sententias, non abiciens ut prauas quas segregatim habeo ut utiles, sensum non meis, sed iam saepe praefati uiri uerbis expositum, breuiter adtraxi, ut potui; atque lectionis causae compendio, unicuique

\footnotetext{
2. In nomine Domini nostri Iesu Christi $R$ rata $R$

4. $\operatorname{cum} R$

5. ex $S$

6. historia $R$

7. is $S$ Marr. : his $R$

9. his $R$

10. imbribus coni. Marr. : nimbibus $S R$

11. haustis $S$ : austus $R$ : auctus Marr.

12. eas\#\#\# R: eaque Marr.

13. occurr\#\#\# R : occurrentium Marr.

14. \#\#\#traxit $R$

15. patris $R$

16. fragilitatis $R$

17. sensus conieci : sensui $S R$

18. meoque $R$
}

3. Incipit praefatio sancti Oddonis in expositione libri Iob ex libris Moralibus deflo-

8. quodammodo coni. Guglielmetti : quoniam (qm) $S R$

RB 20 
sententiae misticum moralemque, sicut repperi, subieci sensum, ne uagans animus dum huc illucque quaereret sensum, ut saepe adsolet, amitteret intellectum.

Libuit etiam primas historiae litteras discretionis causa minio scribere, ut dum historia agnoscitur, expositio historiae utilius carpatur, ne forte dum a rudibus ignoratur sensus patenter expressus obscurius implicetur.

Ergo teneant ${ }^{19}$ sibi illa quibus est facultas numerosa adgregare uolumina, quibus sensus intellectusque uiget, quibus suppetit non tantum enucleata, uerum etiam in aenigmate prolata cognoscere, dum saltem mihi meique ${ }^{20}$ similibus concedant hunc operis exigui penuriae causa coeptum meditari ${ }^{21}$ libellum.

\section{EXPLicit PRAEFATIO PRIMA \\ INCIPIT EIVSDEM ${ }^{22}$ OPERIS SECVNDA}

Gregorii sancti nitidos percurrere campos

Vt coepi, micuere quidem ceu sidera caeli

Verba salutifera, nostros componere ${ }^{23}$ mores

Quae norunt nimium et duras mollescere mentes,

5 Lumine praeclaro et tenebras depellere tetras:

Cuius ab ore fluens fluuius per compita mundi

Pronesiae ${ }^{24}$ pariterque sophiae clare refulget,

Lucidior auro, uitro praeclarior ${ }^{25}$ omni,

Mellifluo gustu cuncta redolentia uincens.

$10 \mathrm{O}$ mens flenda nimis, se quae ${ }^{26}$ subtraxerit $^{27}$ istis

Mellifluis undis, caelo uenientia linquens

Et peritura sequens, nulli quae ${ }^{28}$ profuit umquam!

$\mathrm{O}$ si mille forent doctae mihi milia linguae,

Mille meumque sonos posset ${ }^{29}$ depromere guttur,

15 Aerea uoxque mihi posset dare ferrea uerba,

Hac in laude uiri, totus quem ${ }^{30}$ concinit orbis,

Vt digna fieri possent quae pauca relatu!

Praesulis exstantis ${ }^{31}$ nitor componere carmen

Qui meruit cunctos hominum cognoscere sensus,

20 Et potuit uerbis prauos ostendere mores,

Qui docuit resecare malos de corpore motus ${ }^{32}$,

19. teneo $R$

20. meique $R$ : meisque $S$

21. mediatre, corr. meditari $S$

22. eidem $S$

23. \#\#ponere $S$

24. pronesiae [Phronesis] Marr.

25. quoque clarior $R$, ubi quoque manus recentior in ras. addidit

26. qui $S$

27. subtraxerit $S$ Marr. : subtraxit $R$

28. nulli quae Marr. : nullique $S R$

29. deset, corr. posset $S$

30. quam $S$

31. exstantis conieci : exstanti $S$ : ithentente

32. $\operatorname{motos} S$ 
Et monuit placidos in mente ${ }^{33}$ recondere ${ }^{34}$ mores,

Virtutum reserans fontem et pariter uitiorum.

Hic modice reflexit iter percurrere sacram

25 Historiam Iobab, cuius per compita mundi

Laus ueneranda nitet, quadro ${ }^{35}$ quem climate tensa

Aecclesia reboans laudat; hunc arbiter ipse,

Ore suo laudans, monuit uenerare ${ }^{36}$ per orbem.

Ex qua mirifice ter $^{37}$ bina uolumina condens

30 Tradidit aecclesiae plures distincta ${ }^{38}$ libellos,

Qui ceu prata uirent diuerso gramine fulta

Floribus aspersa redolent pulcherrima uisu :

Hinc etenim uiolae rutilant, hinc ${ }^{39}$ lilia candent,

Emicat hinc rosa, narcissus seu nardus, amomum ${ }^{40}$,

35 Cum uariis fragrant ungentis balsama iuncta.

Hos ego florigeros cupiens percurrere campos,

Multigenosque ${ }^{41}$ mihi perpes decerpere flores,

Extensis manibus nitebar carpere iamque,

Cum subito stupuere meae ceu marmora plantae,

40 Obriguere manus, coepit pallescere uultus,

Sensus et extimuit ${ }^{42}$ crebra suspiria iactans

Vocibus et magnis quasi sub pondere clamans :

Quis, ait, hos hominum poterit percurrere campos,

Aut quis hos poterit flores decerpere cunctos ${ }^{43}$

$45 \mathrm{Vt}$ stipatus eat, alacerque quiescat in aeuum?

Haec $^{44}$ mea nec uis est, tantum ${ }^{45}$ nec pectoris exstat

Robur, ut eximias ualeam comprendere gazas

Pauper et exiguus, misero de germine cretus.

Magniloqui studeant ista qui grandia poscunt,

50 Est quibus et sensus fortis, quibus exstat anelus.

Sufficiant dum parua mihi quae uascula possunt

Exigua retinere mea, ne ${ }^{46}$ grandia poscens

Amittam modica. Quapropter grandia linquens

Hoc opus exiguum coepi non corde coturnus ${ }^{47}$,

33. <in> mente coni. Orlandi: mente $S R$

34. recordare $S$

35. claro $R$

36. uenerari $R$

37. \#\#r S

38. distincte $S$

39. hic $S$

40. ammonum $S$

41. multigenasque $S$

42. extimuit $S$ : extimuit, inter lineas ead. man. extabuit $R$

43. has ... cunctas $S$

44. hac $S$

45. tantus $S$

46. nec $S$

47. coturnus conieci : coturno $S R$ 
55 Arbiter haec nouit superus ${ }^{48}$ qui sidera sentit.

Non ergo hoc spernant modici, non ${ }^{49}$ illa supremi.

Hoc teneant hebetes, teneant sed et illa sagaces:

Illa sciant iuuenes, discant hoc denique nati ${ }^{50}$,

Illa quidem norunt magnos ${ }^{51}$, hoc pascere paruos :

60 Illa dapes tribuunt, nouit hoc porgere ${ }^{52}$ lacte $^{53}$.

48. superus Marr. : superius $S R$

49. non coni. Orlandi: nec $S R$

50. noti $R$

51. agnos $S$ Marr. : magnas $R$

52. porrigere $R$

53. lacte $R$ : lecte $S$ : lacten $M a r r$ : 